التفاعل بين أنماط الإبحار في محتوى المقرر الإلكتروني والتنظيم الذاتي للتعلم على التحصيل الدراسي في التصميم التعليمي والرضا عن بيئة التعلم لدى طلاب كلية التربية

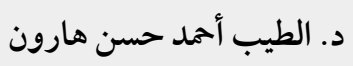


التفاعل بين أنحاط الإبحار في محتوى المقرر الإلكتروني والتنظيم الذاتي للتعلم على التحصيل

الدراسي في التصميم التعليمي والرضاعن بيئة التعلم لدى طلاب كلية التربية

$$
\text { د. الطيب أحمد حسن هارون }
$$

أستاذ تكنولوجيا التعليم المشارك، كلية التربية، جامعة الزعيم الأزهري، الخرطوم، السودان، ta@aau.edu.sd

\section{قبلت للنشر في 2021/ 20 - 20 20 20}

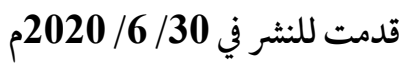

ملخص: هدفت الدراسة إلى الكشف عن أثر بنية الإبحار، ومستوئ التنظيم الذاتي، والتفاعل بينها علن التحصيل الدراسي والرضا لدىن طلاب كلية التربية. تم استخدام المنهج شبه التجريبي والتصميم العاملي للتباين (3x3) للكشف عن أثر المتغيرات المستقلة علن المتغيرات التابعة. بالإضافة إلى دراسة

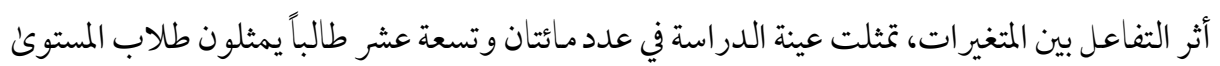
الثالث بمرحلة البكالوريوس بكلية التربية. تم تدريس المفحوصين مقرر التصميم التعليمي باستخدام ثلاثة أنماط مختلفة من نظم الإبحار الهرمي، والشبكي، والهجين. تمثلت أدوات الدراسة في اختبار تحصيلي، ومقياس التنظيم الذاتي، ومقياس الرضا عن بيئة التعلم. أظهرت النتائج أن المتعلمين ذوي التنظيم الذاتي عال المستون تفوقوا علن المتعلمين ذوي التنظيات المنخفضة المستون في التحصيل الدراسي، وفي مستوئ الرضا. عدم وجود فروق ذات دلالة إحصائية للمعالجات الثلاثة. لمريكن لنمط الإبحار المستخدم في هذه الدراسة تأثير علئ تعلم الطلاب وعلئ مستوى الرضا عن بيئة التعلم. وجود تفاعل ملحوظ بين مهارات التنظيم الذاتي ونظام الإبحار. يتعلم الطلاب ذوو التنظيم العلي المستون بشكل أفضل من خلال الإبحار الهرمي وأقل مع الإبحار الخطي، في حين يتعلم ذوي التنظيم الذاتي

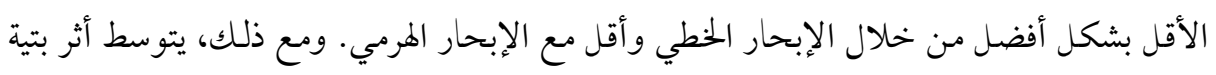

$$
\text { الإبحار الشبكي الهيكلين الآخرين للملاحة لجميع المعالجات التجريبية. }
$$

الكلمات المفتاحية: نظام الإبحار، المقرر الإلكتروني، التنظيم الذاتي، الرضا عن بيئة التعلم، التحصيل

$$
\text { الدراسي }
$$




\title{
The Effect of Navigation Structure in Electronic Courseware and Self- Regulated Learning on Achievement in Instructional Design and Satisfaction for Undergraduate Teacher Students
}

\author{
Dr. EltayebAhmed Hassan Haroun
}

Associate Professor of Educational Technology, College of Education, Alzaiem Alazhari University, Sudan.

ta@aau.edu.sd

Received in June 30, 2020

Accepted in October 2, 2021

\begin{abstract}
This study aims at identifying the effects of navigation structure in electronic courseware, and student self-regulation level on achievement in instructional design and satisfaction towards learning environment for undergraduate students. A quasiexperimental (3x3) factorial ANOVA design used to explore the main effects the independent variables. Two hundred nineteen respondents selected from third class undergraduate students in the faculty of education at Ablaba University. The respondents randomly assigned into one of three treatment groups varied in navigation structure. The treatment group used linear, hierarchical, and network navigation respectively. The tools consist of, achievement test, student's satisfaction scale, and self-regulation scale. The results showed that high-level self-regulated learners outperformed low-level self-regulated learners in achievement, and in satisfaction scale. There were no significant differences for the three treatments; the navigation structure employed in this study had no effect on participants' learning and satisfaction. A significant interaction seen between leaning self-regulation skills and navigation structure. High-level self-regulated learners learn better from hierarchical navigation and less with linear navigation weak-level self-regulated learners learn better with linear navigation and weak with hierarchical. However, the network navigation structure mediates the two other navigation structure for all treatment group.
\end{abstract}

Keywords: Navigation structure, Courseware, Self-Regulated Learning, Satisfaction, Achievement 
لقد ظهر الاهتمام بالتعلم الإلكتروني في الثمانينات من القرن العشرين الميلادي، وتناولت العديد من الدراسات مجموعة من الأسئلة والقضايا المهمة التي أثارتها ثورة التعلم الإلكتروني آنذاك ودعت إلى الاهتمام بالبحث العلمي في بجال التعلم الإلكتروني، فأبرزت بعض الفوارق العميقة بينه وبين التعلم بو اسطة الكتاب المدرسي، وكشفت عن التغيرات التي يجب أن تصاحب تلك الثورة التقنية في التعليم سواء في بجال المسلمات والفرضيات الأولية حول التعليم والتعلم، أو في نظريات التعلم، أو في مجال أساليب القياس التربوي، والسياسات التربوية أو أثر هذه التقنية في الهوية الشخصية وخصائص المتعلمين، وغيرها من قضايا جديرة بالاهتحام. أوضح لوليس وبراون (Lawless and Brown, 1997) أن بيئات التعلم القائمة علن الوسائط المتعددة تمكن المتعلمين من التحكم في المعلومات التي يكصلون عليها وفي تتابع مسار تعلمهم، ويساعد ذلك في تحقيق تعلم ذي معنى. كذلك ذكر هسو (Hsu, 2006) أن القدرات غير الخطية للويب لها سمات عظيمة في التعليم لذات الأسباب. مع ذلك نجد أن نظم الإبحار غير الخطي كذلك قد تقود إلى التوهان disorientation

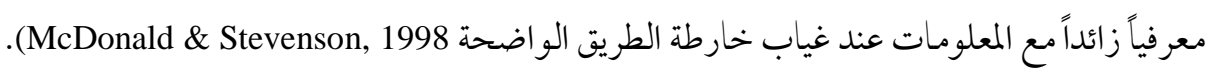
Jacobson \& Spiro, ) بالرغم من مشكلات التوهان في الإبحار غير الخطي. يفترض بعض الباحثين

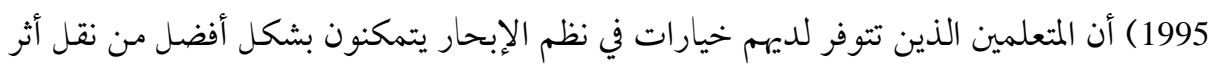
تعلمهم إلى مو اقف جديدة. إن الخصائص الفردية للمتعلمين مهمة في عمليات تصميم وتطوير وتنفيذ المو اد التعليمية والمنهج (Skinner, 1954)، وإن لكل متعلم قدر اته واستعداداته الخاصة وتفضيلاته في عمليات معالجة المعلومات. وإن دراسة آثار الفروق الفردية في عملية التدريس والتعلم، ومن القضايا التربوية المهمة على العموم وفي مجال التعليم المعتمد على الحاسب الآلي والتعلم الإلكتروني وفي تصميم و تطوير بيئات التعلم، وتعزيز جوانب القوة ومعالجة جوانب الضعف. 
ومما لا شك فيه أن المحتوين الإلكتروني بأبعاده المختلفة من بناء مفاهيمي، وأهداف وتسلسل

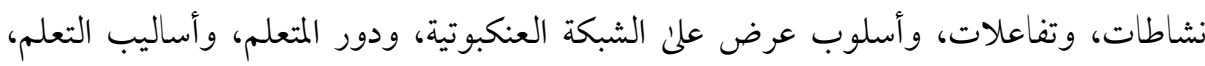
والتقويم يشكل جوهر نظام التعلم الإلكتروني، فهو ليس بجرد وضع مقرر تقليدي علن الشبكة

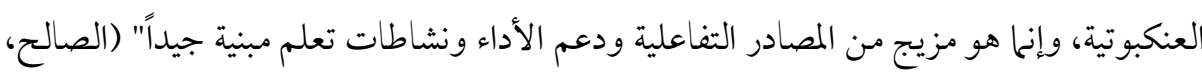

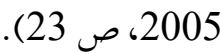

وقد أشارت نتائج دراسة أبو حديد (2004) إلى أن تصميم المحتوين التعليمي وتنظيمه في إطار من العلاقات المتفاعلة ساعد المتعلمين علن تنظيم بنيتهم المعرفية، ومن ثم تمكنهم من استخدام طرق الحل المناسبة بعد استبصار الموقف أو المشكلة، ومن ثم زيادة تحصيلهم في المهارات الأساسية. "ويصمم المحتون في بيئات التعلم الإلكتروني علن هيئة قطع صغيرة من المعلومات تقدم في ما

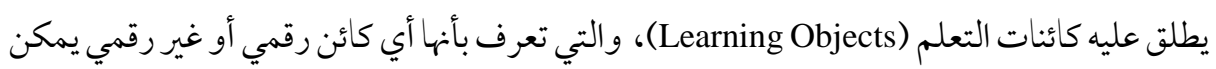
أن يستخدم أو يعاد استخدامه أو يرجع له في التعلم المعزز بالتقنية " (Wiley, 2002, p. 3). ويمكن الوصول إلن أجزاء المعلومات وإطار اتها عن طريق الروابط Links، فهي الأداة التي يتم

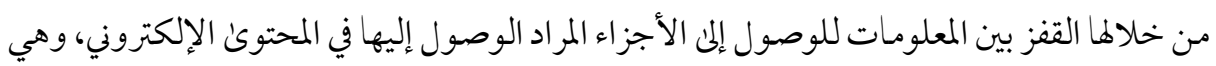

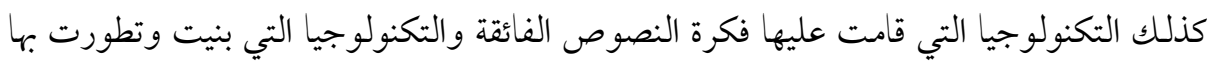
المحتويات الإلكترونية" (Carmen, et al., 2004,p. 277).

لقد تناولت العديد من الدراسات والأبحاث الأنماط المختلفة لنظم الإبحار، فقد ذكر شانك

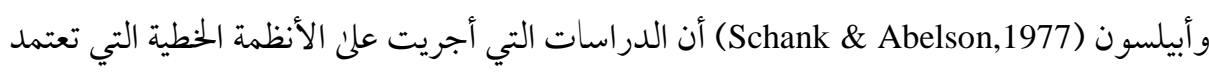
علن الكمبيوتر، تؤكد علن أن الوصول الخطي للمعلومات يساعد في فهم البشر للمعرفة المعروضة

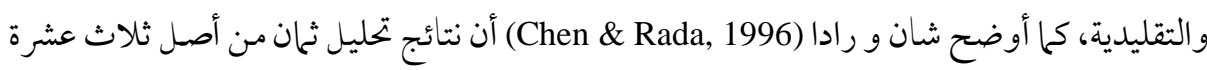

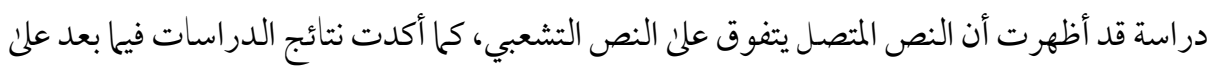
تأثير بنية الرسالة وليس الوسيلة التي تظهر بها الرسالة علن مستوئ الفهم. 
ووجدت دراسة تم إجراؤها علن النصوص بأن السرد المستقيم والتوضيحي من شأنه أن يعمل

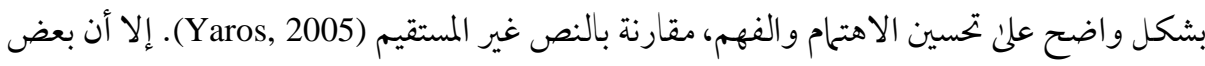
الباحثين تحقق من أوجه الشبه بين النمط غير الخطي علني شبكة الإنترنت وبين الأداء غير الخطي للعقل

.(Shirk, 1992)

إن دراسة التفاعل بين الاستعداد والمعالجة Aptitude-Treatment Interaction ATI من

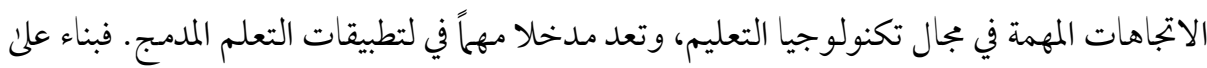
قاعدة الفروقات الفردية في النظرية المعرفية نجد إن خصائص التصميم أكبر تأثيرًا في المتعلمين الأقل

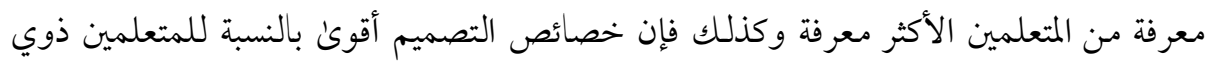
المهارة الفراغية العالية من المتعلمين ذوي المهارة الفراغية المتدنية (ماير، 2004). وهذا يؤكد أهمية

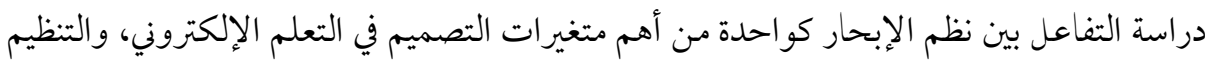

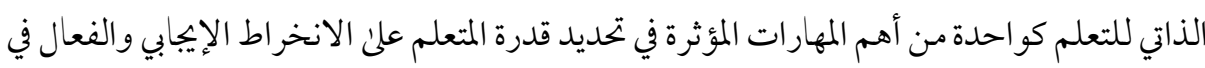
أنشطة التعلم الإلكتروني.

مشكلة الدراسة

لكي يمقق المقرر الإلكتروني الأهداف التي يسعي لتحقيقها، وبغض النظر عن عتون التعلم

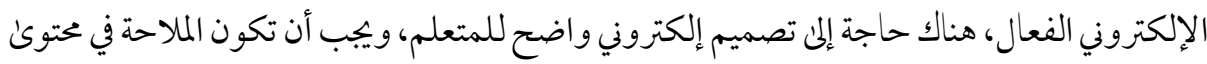

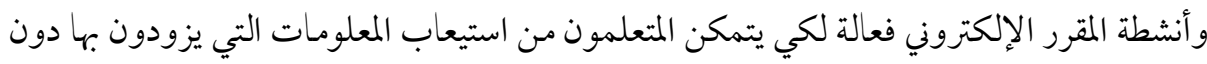

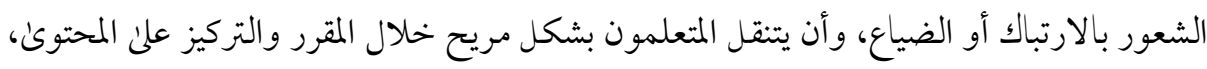

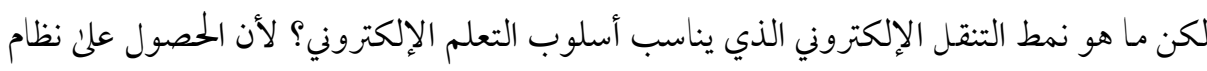

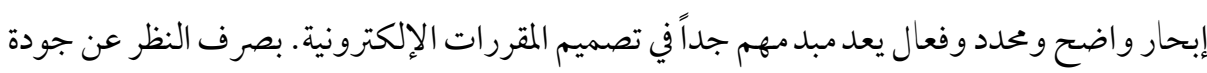

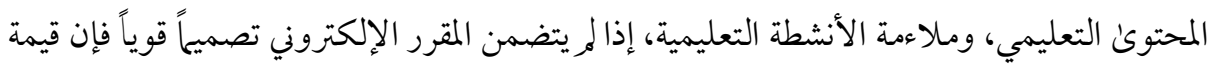

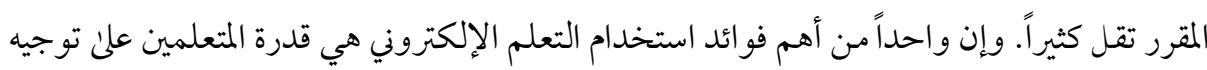

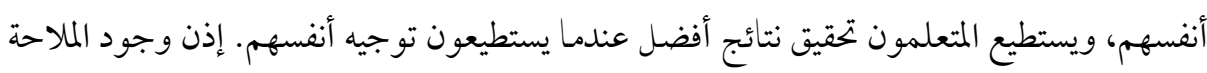


الفعالة والو اضحة أمر ضروري وحيوي لتطوير المقررات الإلكترونية عبر الإنترنت. ولن يكون المقرر

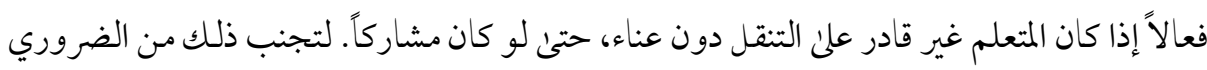
جداً تخصيص بعض الوقت لتصميم نظام الإبحار في المقرر الإلكتروني. لمريعد الهدف من العملية التعليمية تقيم المادة التعليمية بطريقة موحدة إلى جميع المتعلمين، وقد العديد من الباحثين علن ضرورة مراعاة الفروق الفردية بين المتعلمين ووضعها في الاعتبار عند إعداد المواد التعليمية وتصميم المقررات، وضرورة المواءمة بين طرق تقديم المواد التعليمية والفروق الفردية بين المتعلمين. ذلك من أجل تهيئة فرص أفضل للمتعلمين لكي يتعلم كل منهم وفق قدراته واستعداداته. و انطلاقًا من هذا المبدأ ظهرت أهمية التركيز علن دراسات التفاعل بين الاستعداد والمعالجة .Aptitude-Treatment Interaction (ATI)

يشتمل التعلم المنظم ذاتياً (SRL) علن الجموانب المعرفية، وما وراء المعرفية، والسلوكية، والدافعية (التحفيزية)، و العاطفية نحو التعلم. ومن ثم فهو مظلة يتم فيها دراسة عدد كبير من المتغيرات التي تؤثر في التعلم مثل الكفاءة الذاتية، والإرادة، والاستراتيجيات المعرفية، في إطار شاملـ. لهذا أصبح التعلم المنظم ذاتيًا واحدًا من أهم بجالات البحث في علم النفس التربوي. تشكل نماذج التعلم المنظم ذاتيا إطارا متكاملاً ومتماسكا يمكن من خلاله إجراء الأبحاث. ويعد إطارًا مفاهيميًا أساسيًا لفهم Pintrich, 2000, Zimmerman, 1986, Sitzmann \& الجو انب المعرفية والتحفيزية والعاطفية للتعلم (Ely, 2011). تشير مهارات التنظيم الذاتي إلى مهارات عمومية لمعالجة المشكلات ومرقبة الشخص لذاته. هذه المهارات يطلق عليها مهارات ما وراء الإدراك أو مهارات الإدراك الإسمي لأنها ليست استراتيجيات أو عمليات أداء محددة داخلة في حل مشكلة بعينها، أو تنفيذ إجراء بعينه وإنها تشير إلى نوع المعرفة الذي يمكن الفرد من التأمل في أدائه (فلافيل، 1976). وهو موجود لدني المتعلمين الناضجين ويتخذ طابع معالجات التحكم التنفيذي، أي دور المراقب في كثير من نماذج الذاكرة. 
تتمثل مشكلة الدراسة في الكشف عن أثر بنية الإبحار في عحتوين المقرر الإلكتروني ومستوىن

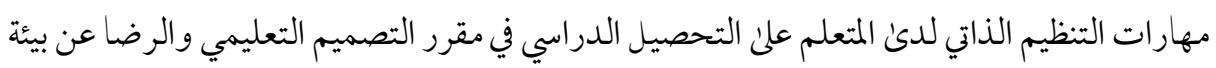
التعلم لدن طلاب البكالوريوس بكلية التربية جامعة الباحة بالمملكة العربية السعودية.

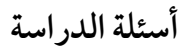

تسعئ الدراسة للإجابة عن السؤال الرئيس المتمثل في: ما أثر التفاعل بين نمط الإبحار في

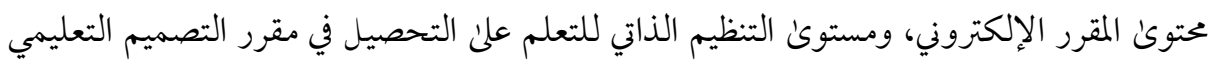

والرضا عن بيئة التعلم المدمج لدن طلاب البكالوريوس بكلية التربية؟

ويتفرع السؤال الرئيس إلى الأسئلة الفرع التالية:

1. ما أثر نمط الإبحار (خطي، شبكي، هرمي) علن التحصيل في مقرر التصميم التعليمي؟

2. ما أثر نمط الإبحار (خطي، شبكي، هرمي) علن الرضا عن بيئة التعلم المدمج؟؟

3. ما أثر التنظيم الذاتي للتعلم (ضـعيف، متوسـط، عال) علن التحصـيل في مقرر التصـميم

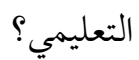

4. مـا أثر التظظيم الذاتي للتعلم (ضعيف، متوسط، عال) علن الرضا عن بيئة التعلم المدمج؟

5. ما أثر التفاعل بين نمط الإبحار (خطي، شـبكي، هرمي) والتنظيم الذاتي للتعلم علن.

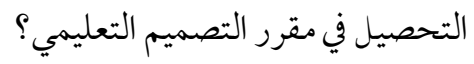

6. ما أثر التفاعل بين نمط الإبحار (خطي، شبكي، هرمي) والتنظيم الذاتي للتعلم علن الرضـا.

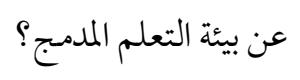

Null Hypothesis الفرضيات الصفرية

للإجابة عن أسئلة الدراسة تم صياغة الفرضيات الصفرية التالية: 
1. لا توجد فروق ذات دلالة إحصائية عند مستوى (05.0=) بين متوسطات درجات الطلاب في اختبار التصميم التعليمي تعزئ لنمط الإبحار في المقرر الإلكتروني لدىن طلاب البكالوريوس بكلية التربية.

2. لا توجد فروق ذات دلالة إحصائية عند مستوى (05=) بين متوسطات درجات الطلاب في مقياس الرضا عن بيئة التعلم المدمج تعزئ لنمط الإبحار في المقرر الإلكتروني لدى طلاب البكالوريوس بكلية التربية.

3. لا توجد فروق ذات دلالة إحصائية عند مستوى (05=) بين متوسطات درجات الطلاب في اختبار التصميم التعليمي تعزئ لمستون التنظيم الذاتي للتعلم لدىن طلاب البكالوريوس بكلية التربية.

4. لا توجد فروق ذات دلالة إحصائية عند مستوى (05.=人) بين متوسطات درجات الطلاب في مقياس الرضا عن بيئة التعلم المدمج تعزئ لمستوى التنظيم الذاتي للتعلم لدى طلاب البكالوريوس بكلية التربية.

5. لا توجد فروق ذات دلالة إحصائية عند مستوى (05.0=) بين متوسطات درجات الطلاب في اختبار التصميم التعليمي تعزئ للتفاعل بين نمط الإبحار في المقرر الإلكتروني ومستون التنظيم الذاتي للتعلم لدئ طلاب البكالوريوس بكلية التربية.

6. لا توجد فروق ذات دلالة إحصائية عند مستوى (05=) بين متوسطات درجات الطلاب في مقياس الرضا عن بيئة التعلم تعزىن للتفاعل بين نمط الإبحار في المقرر الإلكتروني ومستوئ التنظيم الذاتي للتعلم لدئ طلاب البكالوريوس بكلية التربية. 
تسعى الدراسة لتحقيق الأهداف التالية:

1. الكشف عن أثر بنية الإبحار (خطي، شبكي، هرمي) علن التحصيل في مقرر التصميم

$$
\text { التعليم. }
$$

$$
\text { 2. الكشف عن أثر بنية الإبحار (خطي، شبكي، هرمي) علن الرضا عن بيئة التعلم. }
$$

3. الكشف عن أثر مستونى التنظيم الذاتي للتعلم (ضعيف، متوسط، مرتفع) علن التحصيل في

$$
\text { مقرر التصميم التعليم. }
$$

4. الكشف عن أثر مستوئ التنظيم الذاتي للتعلم (ضعيف، متوسط، مرتفع) على الرضا عن بيئة

$$
\text { التعلم. }
$$

5. الكشف عن أثر التفاعل بين بنية الإبحار (خطي، شبكي، هرمي) ومستون التنظيم الذاتي

$$
\text { للتعلم (ضعيف، متوسط، مرتفع) على التحصيل في مقرر التصميم التعليمي. }
$$

6. الكشف عن أثر التفاعل بين بنية الإبحار (خطي، شبكي، هرمي) ومستون التنظم الذاتي للتعلم (ضعيف، متوسط، مرتفع) علن الرضا عن بيئة التعلم.

$$
\text { تتمثل أهمية الدراسة الحالية فيما يلي: }
$$

1. ندرة الدراسات في بجال التفاعل بين الاستعداد والمعالجة فيما يتعلق ببنية تصميم المقررات

$$
\text { الإلكترونية ومهارات التنظيم الذاتي للتعلم خاصة الدراسات العربية. }
$$

2. قد تساعد نتائج الدراسة الحالية في تقديم بعض الموجهات في مجال تصميم تطبيقات التعلم

$$
\text { التكيفي استنادا علن مستوى التنظيم الذاتي للتعلم. }
$$


قد تساعد نتائج الدراسة المعلمين و المصممين التعليميين في القرارات المتعلقة ببنية المقررات

4. قد تعين نتائج الدراسة الحالية المصممين والمبربجين في مراعاة بعض المعايير والمواصفات العلمية و الفنية عند بناء المحتوى الإلكتروني مع مراعاة مدى مناسبتها لخصائص المتعلمين. 5. قد تسهم نتائج الدراسة الحالية في فتح المجال أمسام الباحثين لإجراء المزيد من الدراسات و البحوث المماثلة لهذه الدراسة، وخاصة فيا يتعلق بتأثير بناء الروابط في المحتوى الإلكتروني علئ الاهتمام، وزمن التعلم وعلاقتها بمدى فاعلية الروابط.

\section{تم إجراء الدراسة الحالية في إطار المحددات التالية:}

1. اقتصرت الدراسة علن طلاب السنة الثالثة في برنامج البكالوريوس بكلية التربية جامعة الباحة بالمملكة العربية السعودية في التخصصات المتاحة وهي اللغة العربية والدراسات الإسلامية والجغر افيا والتاريخ وعلم النفس.

2. تم تطبيق الدراسة في بعض الوحدات الدراسية في مقرر التصميم التعليمي. وقد اقتصرت أداة الدراسة المتمثلة في اختبار التحصيل الدراسي على الأهداف المعرفية للمقرر وبعض الجوانب المعرفية المكونة لأهداف المهارات النفسحركية. وله تتضمن أداء المهارات لأن تقويمها يتم باستخدام مقاييس تقدير للمنتج المتمثل في مشروع المقرر والذي يستكمل في نهاية العام الدراسي بعد انتهاء إجراءات الدراسة. 3. تم إجراء الدراسة الميدانية خلال العام الدراسي 2016/2015م. 


\section{مصطلحات الدراسة}

الإبحار: هو عملية سير المستخدم داخل المحتون أو المقرر الإلكتروني، وطريقة تصفحه لمحتوياته، ودرجة التحكم الخاصة بالمستخدم أو بالبرنامج باستخدام أدوات عديدة مثل القوائم المنسدلة، وأزرار التحكم والانتقال وغيرها، وله أنماط متعددة. وتأخذ الدراسة الحالية بالأنماط الخطية Hierarchical (Network Navigation) ، والشبكية)، (Linear Navigation) .(Navigation الإبحار الخطي (Linear Navigation): Sequential طريقة الانتقال خلال المقرر في تتابع خطي مستقيم غير متفرع بحيث يسمح للمستخدم بالتقدم إلى الأمام أو الرجوع إلى الخلف، مع إمكانية التوقف أو الخروج من البرنامج.

الإبحار الشبكي (Network Navigation): طريقة الانتقال خلال المقرر من موضع إلى آخر بشكل عشو ائي (غير خطي)، ويتم الانتقال عبر عقد منظمة من الارتباطات التشعبية التي يتم تصميمها بحيث تمثل كل عقدة أو رابط انتقالاً إلى جزيئة أساسية في المقرر.

الإبحار الهرمي (Hierarchical Navigation): طريقة للانتقال خلال المقرر بطريقة تسلسلية منطقية على شكل شجري. وهي طريقة تسمح للمستخدم بالملاحة العشوائية مع فهم البنية الهيكلية العامة للمقرر.

التعلم الإلكتروني: تقديم محتوي تعليم إلكتروني عبر الوسائط المعتمدة علن الكمبيوتر وشبكاته إلى الطالب بشكل يتيح له إمكانية التفاعل النشط مع هذا المحتوى ومع المدرس ومع أقرانه سواءً كان ذلك بصورة متزامنة أو غير متزامنة وكذا إمكانية إتمام هذا التعلم في الوقت والمكان والسرعة التي تناسب ظروفه وقدراته، فضلاً عن إمكانية إدارة هذا التعلم أيضاً من خلال تلك الوسائط (زيتون، 
المحتوى الإلكتروني: كل وثيقة رقمية متعددة الوسائط، رقمية أو تماثلية، منظمة او غير منظمة، متاحة عبر الإنترنت أو قائمة بذاتها. ويستخدم المصطلح في الدراسة الحالية للإشارة إلى المحتوىن المنظم المتاح عبر منصة عبر الإنترنت تتيح للمستخدمين إمكانية الوصول والتفاعل مع هذا المحتوئ. التعلم المدمج: نموذج يدمج بين التعلم الإلكتروني الافتراضي عبر الإنترنت، والتعلم وجهاً-ـ

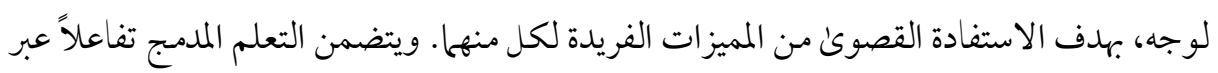
الإنترنت يتراوح بين (30-79\%) من بجمل زمن التفاعل.

التنيم الذاتي (SRL): هو المقدرة علن التوجيه والقيادة الذاتية لعمليات التعلم. ويعبر عنه في الدراسة الحالية بالدرجة التي يجصل عليها الطالب في مقياس التنظيم الذاتي المستخدم في الدراسة الحالية. والتصنيف الذي يجصل عليه الطالب بناء علن درجته في المقياس إلى (مرتفع أو متوسط أو ضعيف) التنظيم الذاتي.

الرضا عن بيئة التعلم (Satisfaction on Learning Environment) تعد خصائص المتعلمين من أهم المتغيرات التي ترتبط بأدائهم في بيئات التعلم الإلكتروني. و تتكون بيئة التعلم الإلكتروني من نظام إدارة التعلم، ومحتوى التعلم، والتفاعل الناتج بواسطة المتعلم الإلكتروني. يتطلب رضا المتعلم في بيئات التعلم الإلكتروني الرضا عن جودة المعلومات السياقية، وكذلك الرضا عن التفاعل بين المعلم والمتعلم، وقد اهتم كثير من الباحثين بالتقييم الكمي للتفاعل بين المعلم والمتعلم ولكنهم لم يهتموا بكيفية حدوث هذا التفاعل (Russell, 1999). يعبر عنه إجرائياً بالرجة التي يجصل عليها الطالب في مقياس الرضاعن بيئة التعلم الذي تم تطويره لأغر اض الدراسة الحالية.

التصميم التعليمي: هو الإجراءات المنظمة لتحليل وتصميم وتطوير وتنفيذ وتقويم مصادر وعمليات التعلم بهدف ابتكار استراتيجيات أو منتجات تعليمية (Dick \& Carey, 1996, p2). 
تصميم التعليم: نظام يهتم بإيجاد أفضل الطرق التي تتؤدي إلى تحقيق الأهداف، فتعمل علن

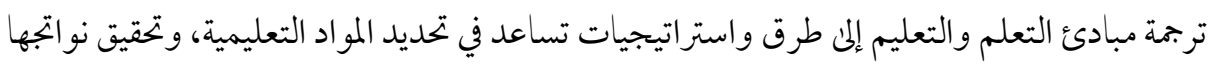
في صورة خخرجات تعلم عقلية وحركية ضمن ظروف بيئية معينة وسياق محدد".

التحصيل الدراسي: يعبر عنه إجرائياً بالدرجة يجصل عليها الطالب في اختبار التحصيل الدراسي الذي تم تطويره لأغراض الدراسة الحالية.

المقرر الإلكتروني (Courseware): المقرر أو المنهج أو المساق الإلكتروني في هذا البحث تعني:

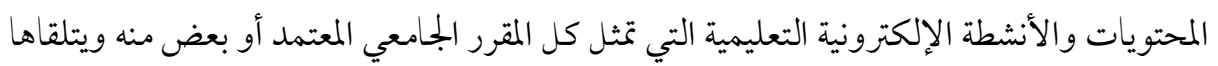

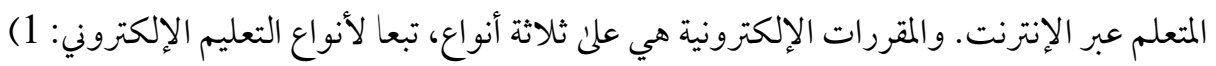
المقررات الإلكترونية المساندة و2) المقررات الإلكترونية المدجة و3) المقررات الإلكترونية المباشرة.

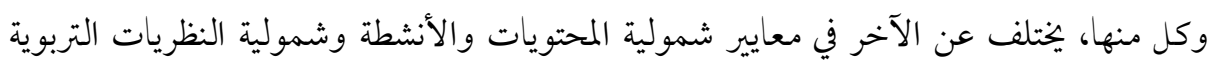

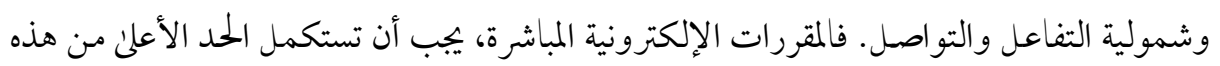

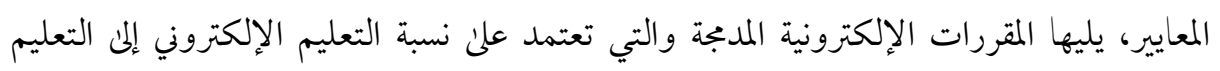

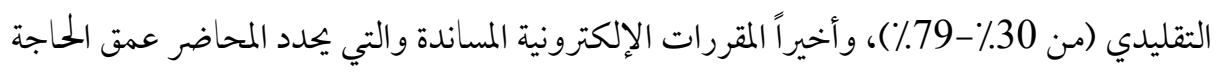
لتلك المعايير.

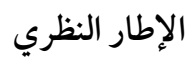

ومن خلال دراسة الباحث لبعض الأسس النظرية ذات الصلة بتنظيم المحتون التعليمي

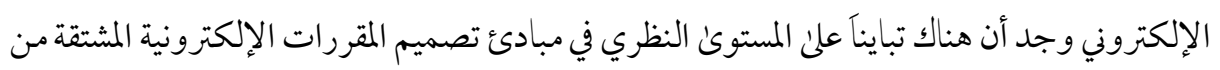

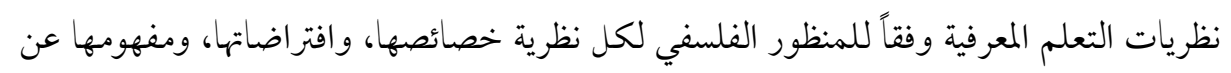

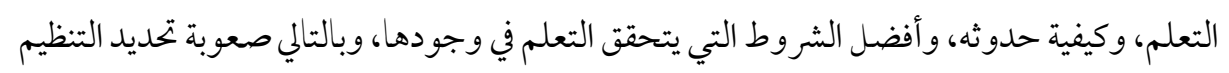

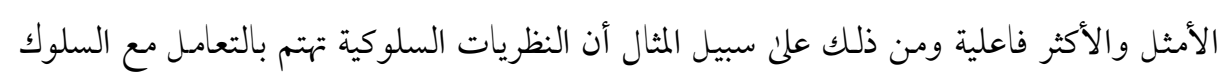

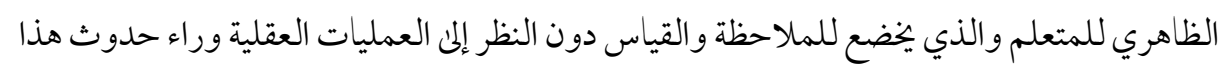


السلوك، بينما يهم أصحاب النظرية المعرفية بالعمليات العقلية التي تحدث داخل عقل المتعلم وينتج

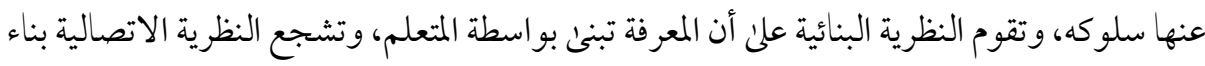

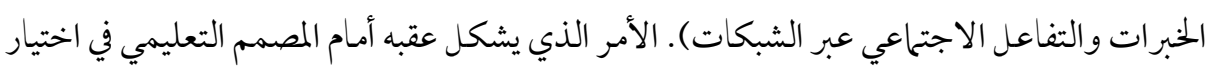
النموذج المناسب.

\section{Schemata Theory نظرية المخططات}

تعد نظرية المخططات من النظريات التي ساهمت في دعم استخدام الروابط في المحتويات

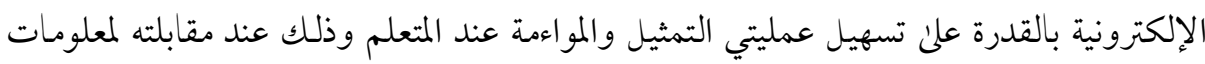

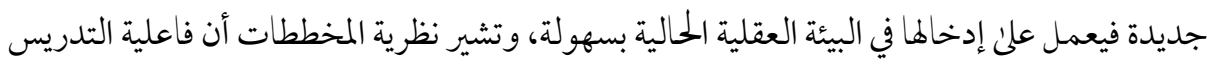

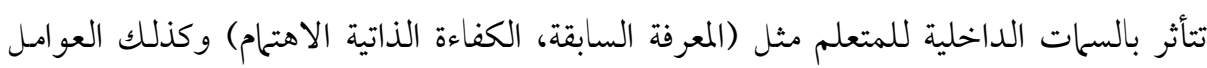

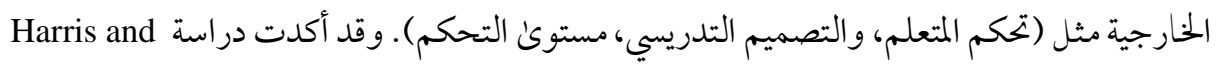
Grantgenett (1993)

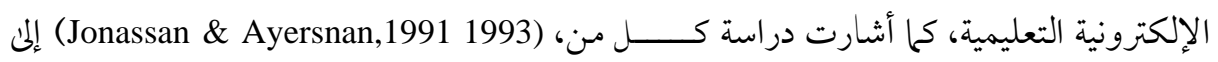

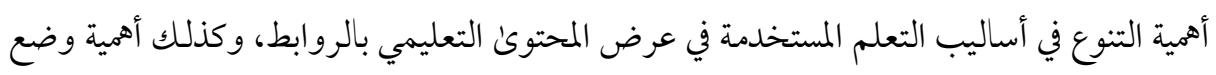

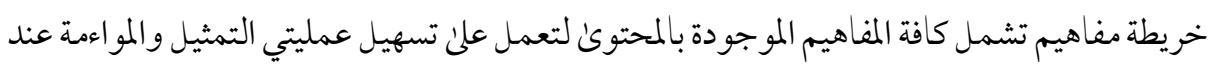
المتعلم.

وهي عبارة عن بنخ معرفة تنظيمية تعمل علن تنظيم المعرفة حول عدد من المفاهيم والمواقف

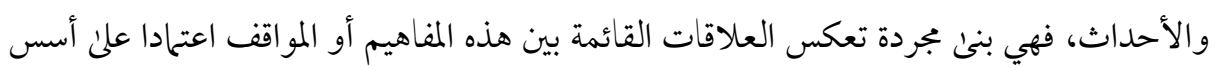
معينة كالتشابه أو الاختلاف بينها أو أي ارتباطات أخرىن.

تؤمن بأن عقل الفرد مكون من أبنية افتراضية ينتزن فيها ما هو معروف، وما يُتعلم من

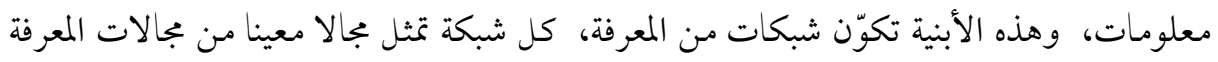

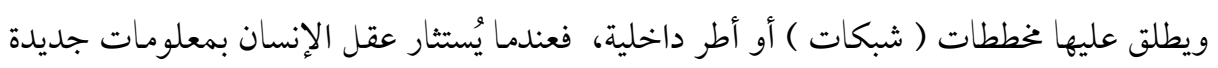


يعرفها أو لا، ثم يقوم بتفسيرها في ضوء خبراته السابقة والمختزنة في هذه الأطر والشبكات، التي تقوم

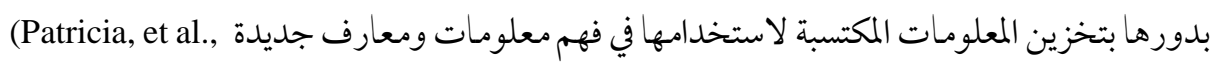
1983, p p 556-557واستراتيجية الخريطة الدلالية تطبيق لنظرية المخطط العقلي في تدريس القراءة عندما يقوم المعلم والمتعلمون بإعادة بناء النص المقروء وتنظيمه في شكل خريطة دلالية لموضوع القراءة تتو افق وتتشابه مع شبكات المخطط العقلي للمتعلم. وهي في ذلك تتفق مع أفكار " أوزبل Ausubel" التي تهتم بتتابع المحتوي التعليمي من العام إلى الخاص، و كذلك المنظمات المتقدمة Advanced Organizers التي تساعد المتعلم علن ربط المعلومات الجديدة بالمعلومات الموجودة عنده ربطا متكاملا لا يتجز أ، وبالتالي يصبح التعلم ذا معنى، ويبقى أثره

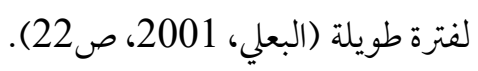
وتفترض هذه النظرية أن هناك مجموعة من مكيانيزمات التجهيز أو المعالجة داخل الكائن العضوي كل منها يقوم بوظيفة أولية معينة وأن هذه العمليات تفترض تنظياً وتتابعاً على نحو معين. وتسعى هذه النظرية إلى فهم سلوك الإنسان حيث يستخدم إمكاناته العقلية والمعرفية أفضل استخدام فعندما تقدم للفرد المعلومات يجب عليه انتقاء عمليات معينة وترك أخرىن في الحال من أجل إنجاز المهمة المستهدفة. وزيادة الاهتحام بالمهارات الإنسانية المعقدة وثورة الكمبيوتر والتطورات في فهم ونمو اللغة، جميعها استثارت الحاجة إلى البحوث المعرفية. وتنظر نظرية تجهيز المعلومات إلى المخ الإنساني باعتبار أنه يشبه جهاز الحاسب الآلي فكلاهما يستقبل المعلومات ويجري عليها بعض العمليات ثم يعطي ويتتج بعض الاستجابات المناسبة، لذا تركز هذه النظرية علن كيفية استقبال المخ للمعلومات ومن ثم

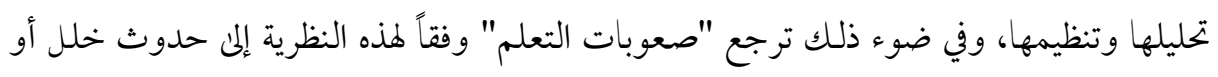
اضطر اب في إحدى العمليات التي قد تظهر في التنظيم أو الاسترجاع أو تصنيف المعلومات. Schema ويتضح مما سبق أن نظرية المخططات تؤكد علن كيفية وضع الفرد لصيغة إجمالية للأحداث وتكوين نظرة كاملة حول كافة الأبعاد المرتبطة بالموقف المشكل للوصول إلى صياغة سليمة

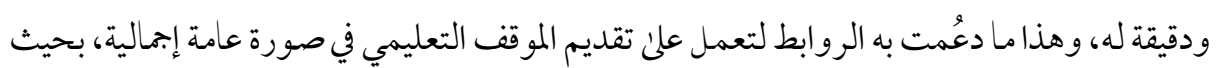


يقوم المتعلم باختيار الجزء الذي يرغب البدء في دارسته مما يساعد علن تكوين الصور الإجمالية العامة

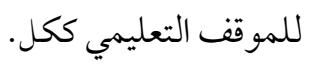

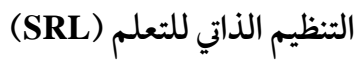
يشير التنظيم الذاتي إلى العملية التي يضع المتعلم من خلالها أهداف، ويخطط، ويستخدم استراتيجيات معينة لتحقيق تلك الأهداف، ويوجه خبرات تعلمه، وير اقب ويعدل سلو كه، ويتحكم في تعلمه لتسهيل اكتساب المعلومات و المهارات (Pintritch, 2000). ويعرف التنظيم الذاتي إجر ائياً بأنه الدرجة التي يجصل عليها الطالب في مقياس التنظم الذاتي الذي يستخدم في الدراسة الحالية. تشير الأدبيات إلى أهمية التنظيم الذاتي. ويذكر (Vrugt \& Oort.2008) أن التنظيم الذاتي يعد أحد أهداف العملية التربوية التي تعمل علن تحسين التعلم حيث يكون المتعلم فعالاً واختيارياً ومتحملاً مسؤولية تعلمه. وقد تعددت التعريفات التي قدمت من قبل الباحثين للتنظيم الذاتي. فقد وصف (رشوان، 2006) التنظيم الذاتي بأنه عملية بناءة نشطة يقوم فيها المتعلم بوضع الأهداف ثم تخطيط وتوجيه و تنظيم وضبط معارفه و دافعيته وسلو كياته والسياق الذي يتم فيه التعلم من أجل تحقيق تلك الأهداف. ويعرف (Bembenutty, 2006) التنظيم الذاتي بأنه العملية التي يضع من خلالها المتعلم أهدافه، ويراقب تعلمه، وينظمه، ويتحكم فيه. ويضيف (Dresel \& Haugwitz, 2008) أن السلوك المنظم ذاتياً هو السلوك الذي يتسم بمستوكن عال من الضبط الذاتي الو اعي، والذي يتضمن التحكم في الأفعال والمعتقدات والمقاصد والرغبات ويؤدي التخطيط دوراً رئيسياً في حياة أصحاب هذا السلوك. أما حسانين (2011) فتعرف التنظيم الذاتي بأنه العمليات التي يقوم فيها المتعلمين بالمشاركة الفعالة و التخطيط والمقصود وبذل الجها مدفوعين برغبتهم الذاتية في استخدام مهارات واستراتيجيات تعلم منظمة ومحددة ومعرفية وما وراء معرفية وانفعالية بغية تحقيق أهدافهم الأكاديمية. 
التعلم الموجه ذاتياً (Self-Directed Learning) يعرفه نولز (Knowles, 1975) بأنه العملية

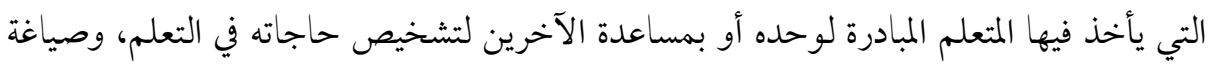

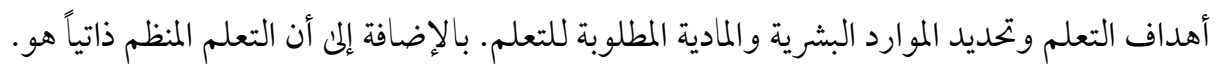

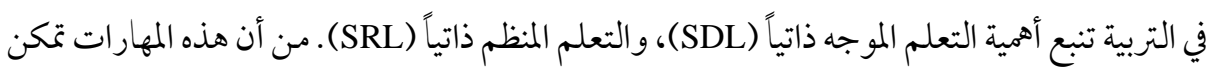

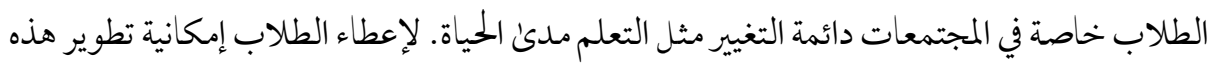

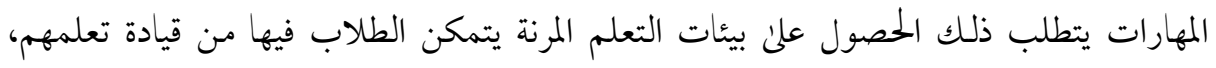

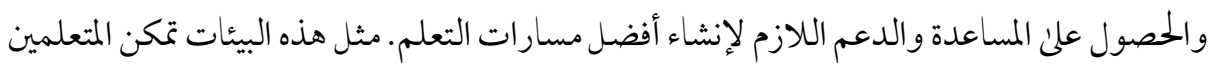
من الحصول علن الحيارات مثل ماذا؟ وأين؟ ومتيل" ولماذا؟ وكيف يتعلم (Hill, 2006).

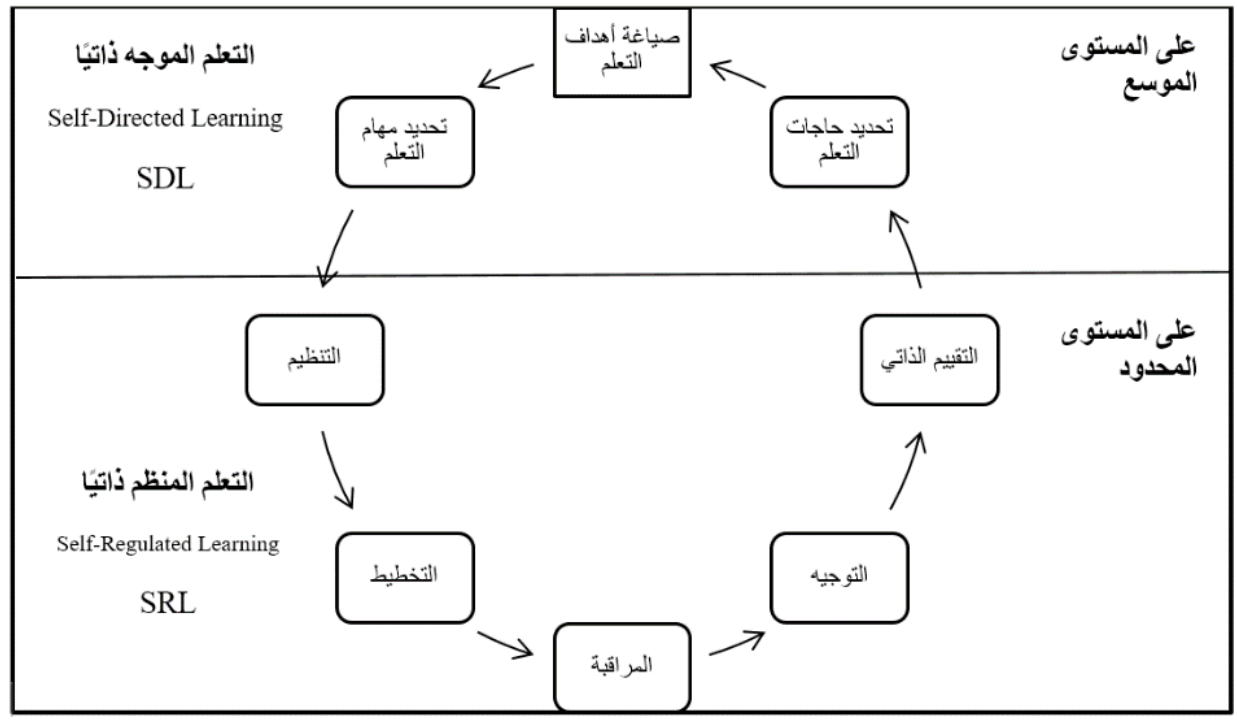

شكل 1العلاقة بين التعلم الموجه ذاتيًا والتعلم المنظم ذاتيًا

بناء علن حاجات التعلم المحددة وأهداف التعلم سيكون المتعلم قادراً علن تحديد الموارد البشرية والمادية في بيئة تعلم مرنة. 
ينظر العديد من الباحثين إلى استراتيجيات التنظيم الذاتي على أنها أساس تفعيل عملية التعلم فهي تمثل مجموعة من السلوكيات أو Zimmerman \& Kitsantas, 2005; Vruget \& Oort, 2005)) الخطوات التي يستخدمها المتعلم لكي تساعده في اكتساب المعلومات الجلديدة وتخزينها واسترجاعها. ونظر أ لأهمية استراتيجيات التنظيم الذاتي، فقد تزايد عدد تصنيفاتها في البحوث والد راسات السابقة، حيث توصلت بعض الدراسات إلى (14) استراتيجية للتنظيم الذاتي والتي يستخدمها التلاميذ لتنظم تعلمهم في البيئات التعليمية المختلفة وهي (التقويم الذاتي، التنظيم والتحويل، وضع الأهداف والتخطيط لها، البحث عن المعلومات، الاحتفاظ بالسجلات والمراقبة، بنية البيئة، مراقبة الذات، التسميع والتذكير، التحاس العون من الأقران، التحاس العون من المعلمين، التماس العون من الراشدين، مراجعة المذكرات، مراجعة الاختبارات، مراجعة الكتب المقررة)، وقامت دراسة كل من Cimmerman \& (بpe \& Wang, 2003) (Martinez-Pons, 1988 العون من الأقران، التماس العون من المعلمين، التحاس العون من الراشدين في استراتيجية واحدة تحت مسمى استراتيجية طلب المساعدة الاجتماعية، كما تم جمع استراتيجيات المراجعة وهي(مراجعة المذكرات، مراجعة الاختبارات، مراجعة الكتب المقررة)في استراتيجية واحدة تحت مسمى استراتيجية مراجعة السجلات، و أصبح التصنيف الجلديد يتكون ( 11) استراتيجية للتنظيم الذاتي. و أظهرت نتائج دراسة كل من (Warr \& Downing, 2000) وجود ثلاثة تقسيات رئيسة للتنظيم الذاتي وهي : استراتيجيات التعلم المعرفية وتتضمن (التسميع، والتنظم، والتوسيع) ، واستراتيجيات التعلم السلوكية وتشمل (البحث عن مساعدة الآخرين، والبحث عن المساعدة من المادة المكتوبة، و التطبيقات العملية) ، واستراتيجيات تنظيم الذات وتتكون من (الضبط الانفعالي، وضبط الدافعية، ومعالجة أو مراقبة الفهم) ومن خلال وصف دراسة (Pintrich, 2000) للتنظيم الذاتي ببنية مكونة من العديد من العوامل المعرفية، وما وراء المعرفية، والدافعية، والاجتماعية المؤثرة على تعلم الفرد وقدرته 
علن تحقيق أهدافه التعليمية، فلقد حددت الدراسة ثلاث استراتيجيات رئيسة هي :الاستراتيجيات المعرفية وتشمل (التسميع، والتوسيع والإسهاب، والتنظيم)، والاستراتيجيات ما وراء المعرفية و تشمل(وضع الأهداف والتخطيط لها، المراقبة الذاتية، وتقييم الذات)، واستراتيجية إعادة المصادر وتشمل(البحث عن المعلومات، وطلب المساعدة الأكاديمية، وتنظيم الوقت، وضبط الجهد، واستعراض السجلات). وفي ضوء العرض السابق لاستراتيجيات التنظيم الذاتي تبنى الباحث في الدراسة الحالية تقسيم استراتيجيات التنظيم الذاتي ل (Pintrich, 2000) حيث إنها تضمنت كل التقسيات التي قام بها الباحثون الآخرون، واهتمامها بالمجال البيئي وتوضيح الكيفية التي يستطيع المتعلم من خلالها تعديل وتغيير بيئنه.

\section{نظرية المرونة المعرفية Cognitive Flexibility Theory:}

تعد نظرية المرونة المعرفية من النظريات التي تشرح لنا كيفية الارتقاء بالتعلم الإنساني عن طريق القراءة والكتابة غير الخطية، حيث إن اكتساب المعرفة الأولية في حالة بجالات المعرفة المبنية جيداً من حيث محتواها يتم عن طريق الممارسة المستمرة والتغذية الراجعة حيث تحدث عملية التعلم

.(Walter,1991)

وتبرز أهمية المرونة المعرفية كوظيفة ذهنية أدائية تساعد الفرد على تغيير وتنويع طرق التعامل العقلي مع الأمور بحسب طبيعتها، بتحليل صعوباتها إلى عو امل يمكن الإحاطة بها والاستفادة منها في إيجاد الحلول، والمرونة المعرفية بُعد مهم من أبعاد الشخصية الإنسانية، وهي تتقبل التغير المفاهيمي و المثابرة في اكتساب أنهاط جديدة من السلوك، والتخلي عن أنماط أخرى قديمة وثابتة، وهي تقع على إحدى طرفي متصل بينما يقع التصلب المعرفي في الطرف الآخر منه (Shaie, Dutta \& Willis, 1991). وتعبر المرونة المعرفية عن قدرة الفرد على التكيف مع استراتيجيات تجهيز ومعالجة المعلومات المعرفية لمو اجهة ظروف جديدة وغير متوقعة في البيئة، حيث إن الطلاب الذين يتصفون بامتلاك مرونة معرفية عالية؛ هم الذين يقومون بتوليد ذاتي للمعرفة من خلال التعديل في المعرفة التي يستقبلونها في 
ضوء خبراتهم السابقة بما يتناسب مع الموقف، مما يساعدهم علن التحرك الذهني في زوايا متعددة للموقف الجديد، وتتضح المرونة المعرفية كلما استطاع الفرد معرفة الخيارات والبدائل الخاصة بموقف ما، وتكييف استجابته حسب متطلبات الموقف الذي يواجهه، إضافة إلى رغبته في أن يكون مرناً

.(Martin, Anderson \& Thweatt, 1998)

وتكما تشير المرونة المعرفية إلى القدرة علن تغيير الاستراتيجيات المعرفية التي يستخدمها الفرد لمعالجة الظروف والمو اقف الجديدة وغير المتوقعة، وهذا التعريف يتضمن ثلاثة عناصر أساسية، أولاً: أن المرونة المعرفية قدرة وبالتالي يمكن أن تكتسب من خلال التدريب ثانياً: يشير إلى تغيير في الاستراتيجيات المعرفية التي يستخدمها الفرد، والتي تعتبر سلسلة من العمليات التي تبحث في حل المشكلة وتشمل تقييم الخصائص المختلفة للمثير وتوليد البدائل والمفاضلة بينها ومن ثم اختيار Canas, ) المناسب. ثالثاً: هذا التغيير يحدث لمواجهة الظروف والمو اقف الجمديدة وغير المتوقعة في البيئة (et al., 2005 الاستجابات استناداً إلما المثيرات والمعلومات الموجودة في الموقف، فعندما تكون هناك مشكلة ما وها عدد كبير من الحلول فإن الفرد المرن هو الذي يقوم ببناء تمثيلات عقلية جديدة أو تعديلات التمثيلات السابقة (Deak, 2003). (20).

وقد أشار بجموعة من الباحثين إلى أن المرونة المعرفية تظهر في سلوك الفرد بشكل كامل وليست تغيراً في السلوك نتيجة لموقف مشكل فقط كما أن هناك بعض العمليات المعرفية التي تر افقهامثل الوعي، Canas et al., 2005; Deak, 2003; Martin et al., ) والتمثيل العقلي، وتوليد البدائل وتقييمها 1998)، والمرونة المعرفية ليست القدرة علن إدراك العلاقات الداخلية بين الأشياء والمفاهيم فقط، ولكنها أيضاً القدرة على إدراك أوجه التشابه والاختلاف بينها، وترتبط المرونة المعرفية بجوانب الاستراتيجيات المعرفية للتعلم المنظم ذاتياً، فالطلبة ذوى المرونة المعرفية العالية لديهم القدرة علن تنظيم معارفهم وخبراتهم، وتعديلها من اجل تحقيق النتائج المتوقعة، كما أنهم أكثر وعياً للعمليات الذهنية والبدائل المتاحة، والتعامل مع الخبرات المعرفية الأكثر تعقيداً، كحا أن تطور المرونة المعرفية يتطلب تدريباً 
يرتبط بنمط شخصية المتعلم، والقدرة المتطورة التي يمتلكها المتعلم للإفادة من الخبرة التي يواجهها، وإن ذلك قد يكون غير متاح للطلبة أثناء الدراسة في الظروف العادية، كما ترتبط المرونة المعرفية بالدافعية بندية

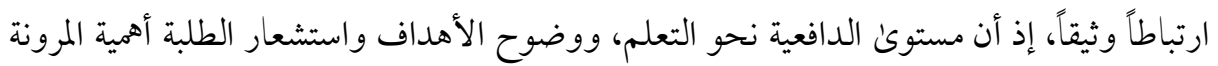

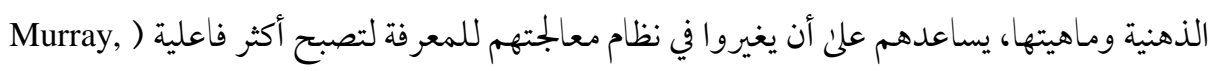
128 (أيوب، 2011، Sujan, 1990 هذا وتتأثر المرونة المعرفية إيجابًا بوجود دافعية عالية ورؤية واضحة، فإن نموها لدئ الطلبة إلى

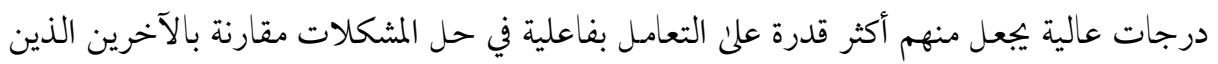

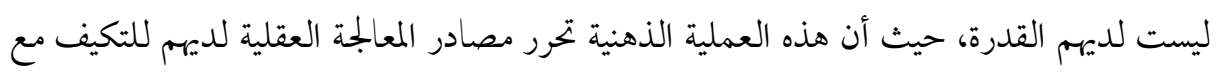

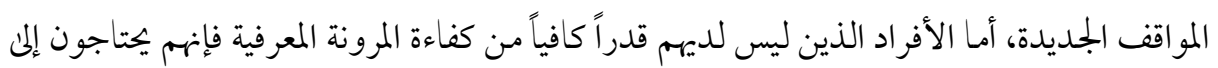

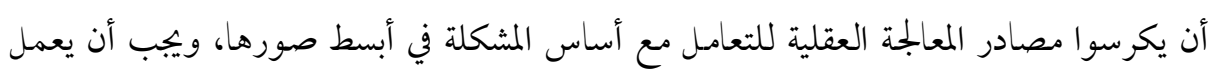

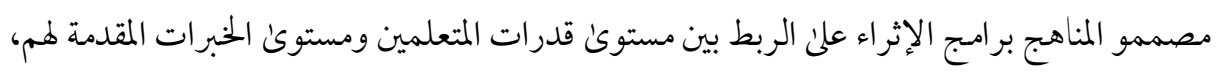

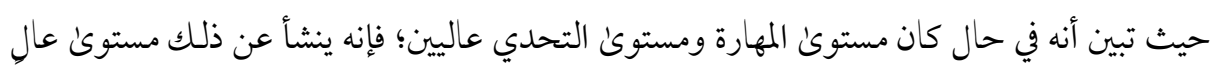

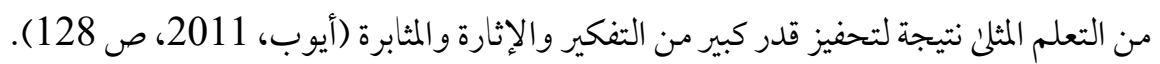

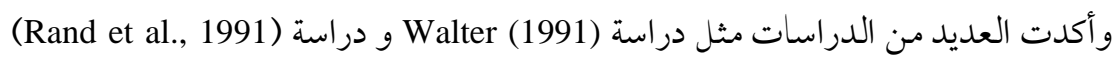
علن أن نظرية المرونة المعرفية دعمت استخدام الروابط في المحتويات الإلكترونية التعليمية بالقدرة علني

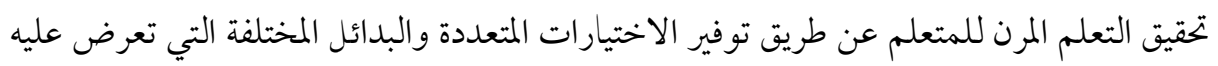

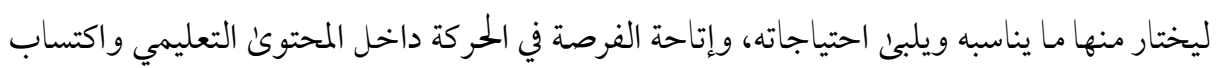

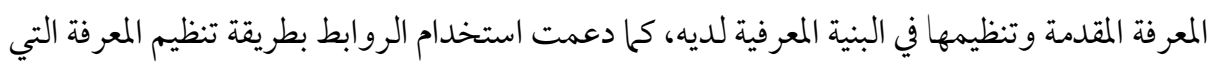

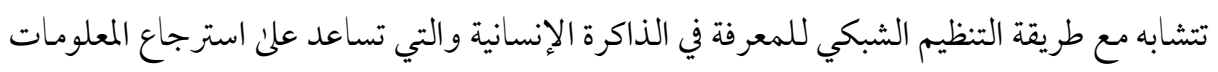

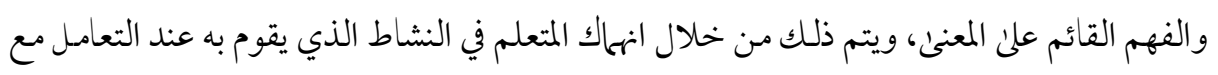
بريجات المحتوي الإلكتروني. 
ويتضح من هذه النظرية إنها تهتم بالارتقاء بالتعلم الإنساني في محاولة اكتساب المتعلم المعرفة ذات التركيب البسيط والقدرة الذاتية علن إعادة تركيب المعرفة الموجودة لديه للاستفادة منها في المو اقف والظروف المتغيرة في بجالات المعرفة المختلفة. وسوف نجد أن الوسائل الفائقة تتيح المرونة المعرفية للمتعلم عن طريق الاختيار ات المتعددة والبدائل المختلفة التي تعرض عليه ليختار منها مـا يناسبه ويلبئ. احتياجاته. وكذلك فإنها تتيح فرصة الحركة داخل المحتوى التعليمي كما تتيح للمتعلم اكتساب المعرفة المتقدمة وتنظيمها في البنية المعرفية لديه.

$$
\text { الدراسات السابقة }
$$

ومن هذه الدارسات دراسة لاي لاي وآخرون (Lai-Lai, et al., 2003) حيث هدفت الدراسة إلى الكشف عن أثر اختلاف أنهاط الإبحار علن التحصيل الدراسي للمتعلمين وكانت الأدوات على Hyperlinks النحو التالي (الإبحار الهرمي Hierarchical، الإبحار الهرمي مع الارتباطات الفائقة Hierarchical with page Hyperlinks with page Sequential محرك البحث Search Engine، وخلصت الدراسة إلى وجود فروق ذات دلالة إحصائية في التحصيل لصالح الإبحار الهرمي. وأجرى أحمد محمد (2005) دراسة هدفت إلى الكشف عن أثر اختلاف نمط الإبحار (الهرمي، والشبكي) على تنمية مهارات إنتاج البرامج التلفزيونية لطلاب شعبة تكنولوجيا التعليم وخلصت إلى وجود فروقات ذات دلالة إحصائية ناتجة عن اختلاف نمط الإبحار لصالح الإبحار الهرمي. كما أجرى أسامة سعيد (2005) دراسة هدفت إلى التعرف علن أثر اختلاف نمط الإبحار (الخطي، والقائمة) علن تنمية مهارات تطبيقات الإنترنت التعليمية لطلاب بكالوريوس تكنولوجيا التعليم وخلصت إلى وجود فروق نتيجة اختلاف نمط الإبحار لصالح الإبحار بالقائمة. وفي دراسة مي شانج وآخرون (Mei-Shang, et al., 2006) والتي هدفت إلى التعرف علئ أثر اختلاف ثلاثة من أنماط الإبحار الارتباطات المعتادة Hyperlinks Regular، الإبحار الهرمي 
Hierarchical Navigation ، القائمة المنسدلة Driven Menu علن التحصيل الدراسي للمتعلمين، وخلصت إلى أن الإبحار الهرمي Hierarchical Navigation كان أكثر فاعلية في أداء المتعلمين. ومن هذه الدراسات دراسة سو وكلين (Su, \& Klein, 2006) والتي هدفت إلى الكشف عن أثث أنماط الإبحار (الارتباط التشعبي، وقائمة المحتويات، وخريطة المفهوم) والثقة بالكمبيوتر علن فئل الأداء والاتجاه نحو بيئة التعلم بالوسائط الفائقة لدئ طلاب الكليات الجامعية. وقد أشارت النتائج إلى الثي أن الطلاب في مجموعة قائمة المحتويات أعلان فيا التحصيل والاتجاه نحو بيئة التعلم. وأن الطلاب في مجموعتي الارتباط التشعبي وخريطة المفهوم كانوا أكثر زيارة للصفحات من مجموعة الارتباط التشعبي المضمنة. علاوة علن ذلك، كان الطلاب ذوي الثقة المرتفعة بالكمبيوتر أفضل بكثير في الاختبار البعدي من الطلاب ذوي الثقة المنخفضة بالكمبيوتر. وهدفت دراسة بيونتام بيكر وغولدشتاين (Puntambekar, \& Goldstein, 2007) إلى التعرف علن تأثير التمثيل المرئي لهيكل المفاهيم للمجال علن العلم و التعلم والتنقل في بيئة النص التشعبي والتي أجريت علن عينة من طلاب فصول الصف السادس في ولاية كونتيتك. وقد تكونت هذه العينة من (80 طالباً) في مادة العلوم. وقد توصلت نتائج الدراسة إلى أن النص المعتمد علن خر ائط المفاهيم و البو صلة يمكن الطلاب من فهم المفاهيم وعلاقتها بالمفاهيم المرتبطة بها بشكل أكبر من الطلاب الذين تعلمو ا من خلال قائمة المفاهيم الملاحية، وربها يعود ذلك إلى أن بنية النص التي تعلمو امن خلالها كانت أكثر ثراء.

كما هدفت دراسة ماكدونالدز وستيفنسون (Mc Donald \& Stevenson, 2007) إلى التعرف علنى آثار بنية النص و المعرفة السابقة للمتعلم على الإبحار في النص التشعبي، تم دراسة أثار ثلاثة من نظم الإبحار (الهرمية، غير الخطية، والمختلطة" هيكل هرمي مع روابط") على أداء الإبحار، وتكونت العينة من (30 طالباً) من طلاب جامعة دور هام، حيث قسمت العينة إلى فئتين؛ فئة ذات دراية بموضوع النص وهم (طلاب الدراسات العليا في علم النفس)، وفئة تفتقد الدراية (طلاب جامعيين في السنة الأولن في علم النفس) . وقد دلت النتائج على أن التصفح والإبحار في بنية النص المختلط جاءت 
في المرتبة الأولى، تلتها بنية النص المرمي، ثم جاءت بنية النصوص غير الخطية في المرتبة الأخيرة. كما

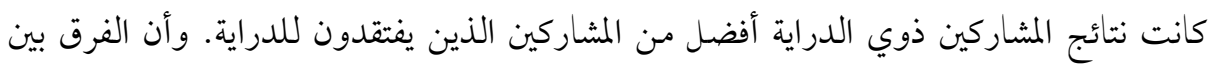
المشار كين ذوي الدراية والمشاركين الذين ليسو اعلن دراية اختفئ مع النص المختلط. وهدفت دراسة إبراهيم (2009): إلى الكشف عن أثر اختلاف استراتيجيتي تصميم الإبحار

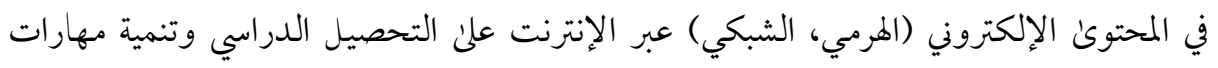

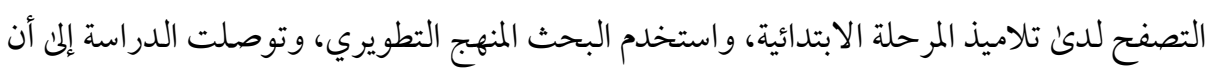

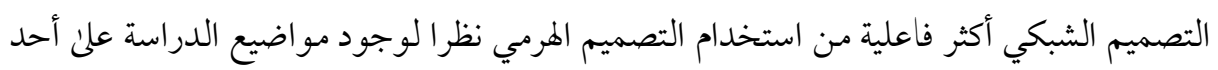

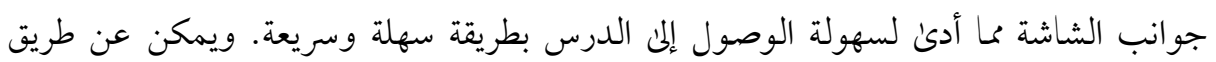

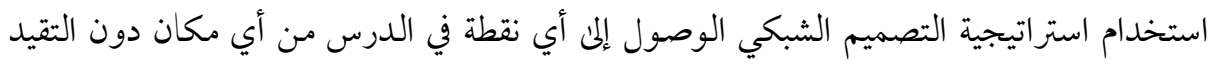

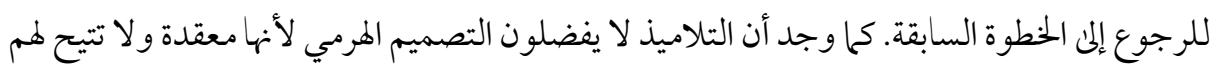

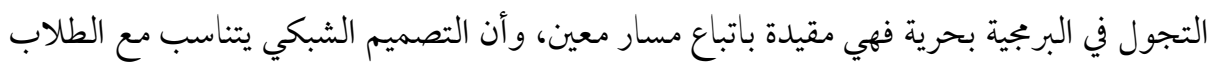

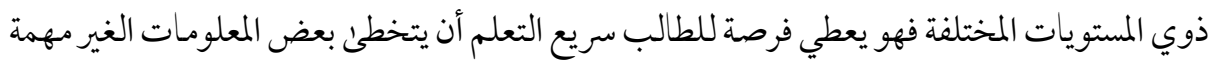
بالنسبة له، وأن استخدام استراتيجية التصميم الشبكي يتسم بالمرونة الكافية. وخلصت دراسة شياء سرور (2010) والتي هدفت إلى الكشف عن أثر اختلاف نمط الإبحار

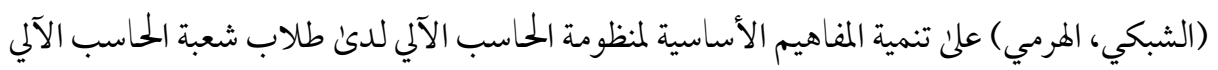
إلن وجود فروق لصالح الإبحار الشبكي. أما دراسة حممد (2010): فقد هدفت إلى التعرف علن أثر التفاعل بين نمط الإبحار (الخطي،

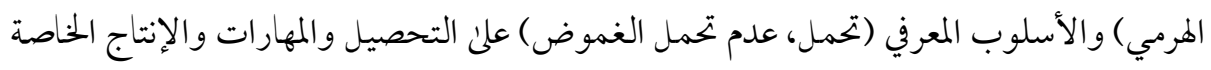

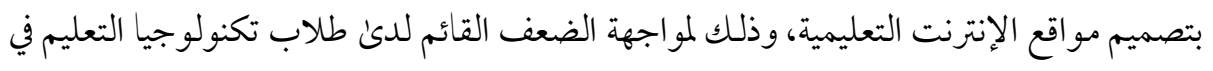

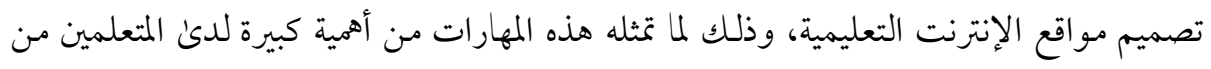

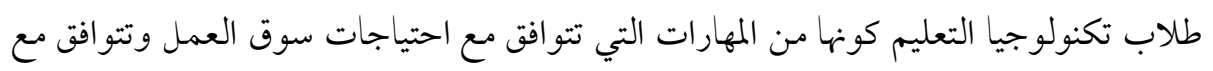
طبيعة تخصصهم التي تتميز بالبحث عن تقنيات جديدة يمكن استخدامها لخدمة العملية التعليمية،

\section{http://dx.doi.org/10.29009/ijres.5.1.4}


ومن أجل ذلك تم إعداد قائمة بمهارات تصميم مواقع الإنترنت التعليمية وتم تمثيلها من خلال موقع يعرض عبر الإنترنت لتنمية هذه المهارات لديهم. وخلصت نتائج الدراسة إلى وجود فرق دال إحصائيا بين متوسطي درجات الاختبار التحصيلي وبطاقة الملاحظة وبطاقة تقييم المنتج النهائي لمهارات تصميم مو اقع الإنترنت التعليمية يرجع إلى الأثر الأساسي للتفاعل بين نمط الإبحار (الخطي، الهرمي) والأسلوب المعرفي (تحمل، عدم تحمل الغموض).

وهدفت دراسة المزيد (2011): إلى التعرف على أثر اختلاف أنهاط الإبحار في ألعاب الحاسب التعليمية علن التحصيل الدراسي في مادة الرياضيات لدى تلاميذ المرحلة الابتدائية وتكونت عينة البحث من (30) تلميذاً من تلاميذ مدرسة ابن تيمية الابتدائية بالرس ، حيث تم تقسيم التلاميذ إلى

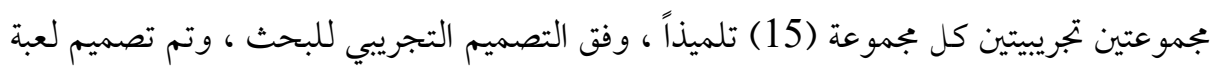
الحاسب التعليمية باتباع نموذج "عمد سلميان السيد" وبعد التأكدمن تجانس المجموعتين التجريبيتين تم تطبيق اللعبة علن المجمو عتين باختلاف نمط الإبحار ، ومن ثم تطبيق أداة البحث المتمثلة في الاختبار التحصيلي. وتوصلت نتائج البحث إلى عدم وجود فروق ذات دلالة إحصائية عند (0.05) بين متوسط درجات المجموعتين التجريبيتين (المجموعة التي درست بنمط الإبحار الخطي والمجموعة التي درست بنمط الإبحار من خلال القائمة).

بينما هدفت دراسة محجوب (2011): إلى التعرف علن أثر التفاعل بين أدوات الإبحار في برامج الكمبيوتر فائقة الوسائل (القائمة - الخريطة - الفهرس) ونمط التعليم (الفردي - في بجموعات صغيرة)، ومستوى السعة العقلية (مرتفع - منخفض) على تنمية تحصيل ومهارات الطلاب في مقرر شبكات الحاسب. وتم اختيار عينة البحث عشوائياً من طلاب الفرقة الثالثة ـقسم تكنولوجيا التعليم ـ بكلية التربية النوعية ـ جامعة بنها، وتم تقسيم العينة المختارة بعد تطبيق اختبار السعة العقلية عليها إلى (12) بجموعة تجريبية كل بجموعة مكونة من (15) طالب وطالبة، وتم اختيار هذه الفرقة لدراستهم لمقرر شبكات الحاسب في الفرقة الر ابعة، ومن ثم فهم ليس لديهم خبرة كافية بمهارات شبكات الحاسب وفي نفس الوقت هم بحاجة ماسة إليها، ولقد بلغ العدد النهائي لعينة البحث (180) طالباً وطالبة. 
واستخدم الباحث المنهج الوصفي التحليلي وذلك عند تحليل البحوث والدراسات السابقة المرتبطة بموضوع الدراسة الحالية، كما استخدم الباحث أيضاً المنهج التجريبي وذلك لتطبيق برامج البحث ثم اختبار أثر التفاعل بين متغيرات البحث. وقد توصلت نتائج الدراسة إلى وجود أثر كبير للتفاعل بين أدوات الإبحار في برامج الكمبيوتر فائقة الوسائل أثر التفاعل بين أدوات الإبحار في برامج الكمبيوتر فائقة الوسائل (القائمة - الخريطة - الفهرس) ونمط التعليم (الفردي - في بجموعات صغيرة)، ومستون السعة العقلية (مرتفع - منخفض) على تنمية تحصيل ومهارات الطلاب في مقرر شبكات الحاسب ونمط التعليم (الفردي - في مجموعات صغيرة) ومستون السعة العقلية (مرتفع - منخفض) على تنمية تحصيل ومهارات الطلاب في مقرر شبكات الحاسب. وهدفت دراسة رونالد (Ronald, 2011) إلى استقصاء تأثير أنحاط الإبحار علن الاهتحام والفهم في مجال العلم والتكنولوجيا لدى طلاب الجمامعة تم استخدام التصميم التجريبي العاملي 2 (النص) × 2 (الرابط) علن قصص هرمية مقتبسة مقابل السرد المستقيم، وقد أظهرت نتائج الدراسة وجود فروق ذات دلالة إحصائية في متغير الفهم لصالح بنى النص المستقيم مع الروابط المستقيمة، ثم جاءت في المرتبة الثانية بنى النص غير المستقيم والروابط غير المستقيمة المتطابقة. أما دراسة إبر اهيم (2013): فقد هدفت إلى التعرف على فاعلية أدوات تقديم المحتـوى القائمة علن تطبيقات التواصل الإلكتروني في تنمية كل من التحصيل المعرفي والأداء المهارن والاتجاه لدني طلاب تكنولوجيا التعليم. استخدم البحث منهجين بحثيين هما المنهج الوصفي التحليلي والمنهج شبه التجريبي، وقد توصلت نتائج الدراسة إلى فاعلية أدوات تقديم المحتوى القائمة على تطبيقات التو اصل الإلكتروني في تنمية مهارات توظيف بعض المستحدثات التكنولوجية لدىن طلاب تكنولوجيا التعليم واتجاهاتهم نحوها. بعد تحليل الدراسات السابقة نجد أن بعض الدراسات قارنت بين أثر نظامين أو أكثر من نظم الإبحار علن متغير أو أكثر من خخرجات التعلم. وتوصلت هذه الدراسات إلى نتائج متباينة وتم تطبيقها في سياقات خختلفة لرتيم التوصل من خلالها إلمى تفضيلات مطلقة حول نظام معين. 
وبعض الدراسات استخدمت متغيرين أو أكثر، مثل نظم الإبحار والتلميح البصري أو خر ائط المفاهيم أو غير ذلك من المتغيرات التصميمية، ودراسات أخرىن درست التفاعل بين نظم الإبحار وخصائص المتعلم، وغالبية هذه الدراسات ركزت علن الأساليب المعرفية أو الخبرة السابقة. إلا أن

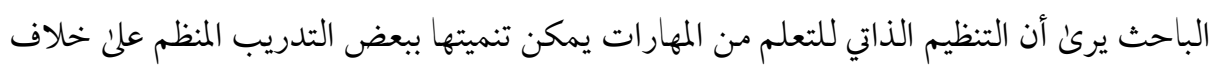
الأساليب المعرفية التي تمثل سمات شخصية يصعب تغييرها لدئ الفرد بالتعلم. وفي المقابل كذلك نجد

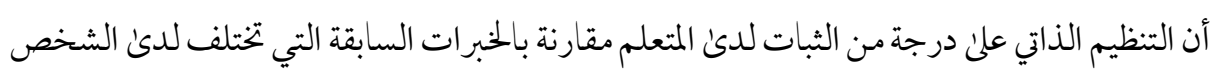
الو احدمن بجال معرفي لآخر . بالتالي فإن نتائج دراسات التفاعل بين نظم الإبحار والتنظيم الذاتي للتعلم يمكن أن تفضي نتائجها إلى أحكام مفيدة في بجال جودة التصميم علن العموم، وفي بجال تصميم المرن و التكيفي.

\section{منهج الدراسة}

تم استخدام المنهج شبه التجريبي Quasi-Experimental من خلال التصميم العاملي للتباين

للكشف عن التفاعل بين أثر أثنين من المتغيرات المستقلة المتمثلة في بنية (Factorial Design 3x3) الإبحار في المقرر الإلكتروني (خطي، شبكي، هرمي)، ومستوئ التنظيم الذاتي للتعلم (مرتفع، متوسط،

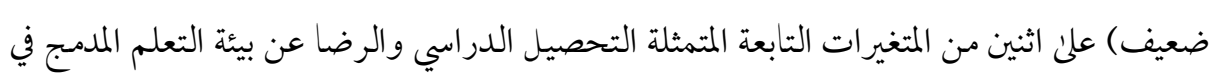
مقرر التصميم التعليمي لدئ طلاب السنة الثالثة بمرحلة البكالوريوس في برنامج البكالوريوس بكلية التربية جامعة الباحة بالمملكة العربية السعودية.

$$
\text { متغيرات الدراسة }
$$

تتمثل متغيرات الدراسة فيما يلي: 
أ- بنية الإبحار في المقرر الإلكتروني وله ثلاث مستويات (خطي Linear، شبكي Network، هرمي Hierarchy). ب- مهارات التنظيم الذاتي للتعلم وله ثلاث مستويات (مرتفع، متوسط، ضعيف) المتغيرات التابعة

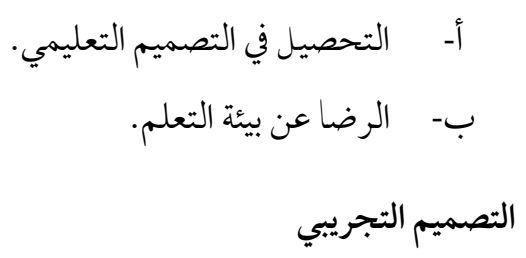
اعتماداً علن بنية الإبحار في محتون و أنشطة المقرر الإلكتروني (خطي، شبكي، هرمي)، ومستوىن التنظيم الذاتي للتعلم (مرتفع، متوسط، ضعيف) تم استخدام التصميم التجريبي العاملي 3x3 لدراسة الأثر الأساسي لمتغير بنية الإبحار، وأثر المتغير التصنيفي (Fractional Factorial ANOVA) المتمثل في مستوئ التنظيم الذاتي (مرتفع، متو سط، ضعيف)، وأثر التفاعل بينها علن متغيري التحصيل الدراسي والرضاعن بيئة التعلم. والشكل التالي يوضح تصميم الدراسة الذي يتضح من الشكل التالي: 


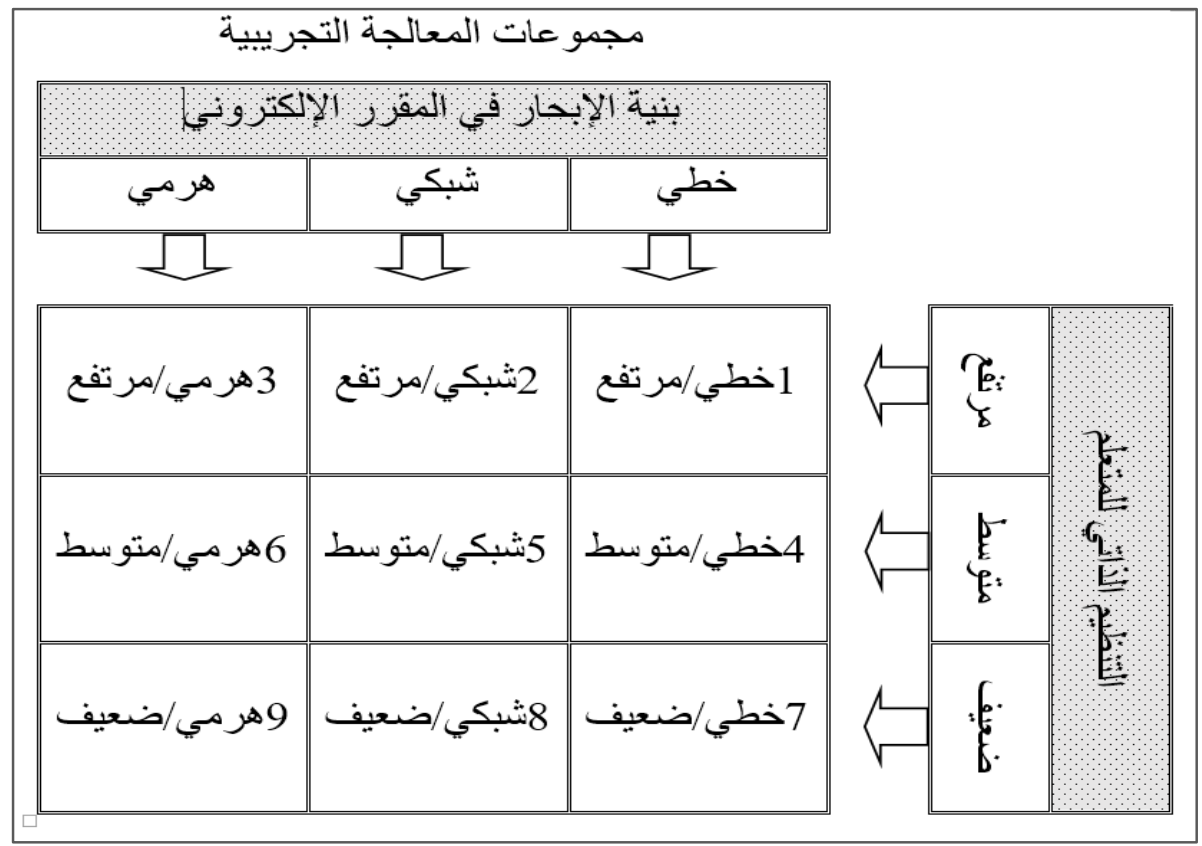

شكل 2 التصميم التجريبي العاملي المستخدم في الدراسة

المجتمع وعينة الدراسة

تمثل مجتمع الدراسة في طلاب السنة الثالثة بكلية التربية جامعة الباحة بالمملكة العربية السعودية في مرحلة البكالوريوس في برنامج البكالوريوس للعام الدراسي 2018/2019م، بلغ عددهم 316 طالباً، بلغ عدد أفر اد العينة التي استوفت متطلبات الدراسة وتنفيذ أدوات الدراسة 219 طالباً، منهم 82 طالب و137 طالبة. تراوحت أعمار المفحوصين بين 21و 51 سنة بمتوسط عمر 35.7 سنة. تم تقسيم العينة بالطريقة العشوائية إلى ثلاث مجموعات وفقاً لنمط الإبحار في المقرر الإلكتروني.

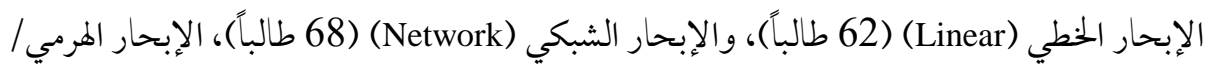
الهيراركي (Hierarchical) (79 طالباً). الجلدول 1 يوضح توزيع المفحوصين علن بجموعات الدراسة وفقاً لنظم بنية الإبحار في المقرر الإلكتروني. 
جدول 1 توزيع المفحوصين علن مجموعات المعالجة التجريبية

\begin{tabular}{|c|c|c|}
\hline & \multicolumn{3}{|c|}{} \\
& & \\
\hline & إبحراء & \\
\hline
\end{tabular}

للإجابة عن أسئلة الدراسة واختبار فرضياتها، اتبع الباحث بجموعة من الإجراءات بدأت بالاطلاع على الدراسات والأبحاث السابقة في بجال أنحاط الإبحار في المحتون الإلكتروني، والتظليم الذاتي للتعلم، ودراسات التفاعل بين الاستعداد خصائص المتعلمين والمعالجات التجريبية. ثم إعداد وضبط أدوات الدراسة، وتصميم مواد المعالجة التجريبية المتعلقة بالمقرر الإلكتروني بأنماطه المتنوعة في نظم الإبحار، وتطويرها، وإعداد بيئة التعلم الإلكتروني التي تسمح بتطبيق الدراسة، بالإضافة إلى إجراءات تطبيق أدوات الدراسة، ورصد النتائج ومعالجتها. للإجابة عن أسئلة الدراسة ومناقشة التتائج وتفسيرها وتقديم التوصيات المقترحات. وذلك وفق الخطوات التالية.

$$
\text { إعداد أدوات الدراسة }
$$

تمثلت أدوات الدراسة المستخدمة لجمع البيانات اللزمة لاختبار الفرضيات في اختبار التحصيل الدراسي، ومقياس الرضا عن بيئة التعلم، بالإضافة مقياس التنظيم الذاتي للتعلم المستخدم في تصنيف المفحوصين بناء على متغير الدراسة الوسيط (Moderator). وقد إعداد أدوات الدراسة واستخراج دلالات الصدق و الثبات بو اسطة الباحث، وذلك وفق الإجر اءات التالية:

أولاً: اختبار التحصيل الدراسي: تم إعداد اختبار تحصيلي في مقرر التصميم التعليمي وفق الإجراءات 
تحديد الهدف من الاختبار: حيث تمثل الهدف من الاختبار في الحصول علن مقياس على درجة مناسبة من الصدق والثبات والموضوعية لقياس التحصيل الدراسي في بعض والوحدات الدراسية من مقرر التصميم التعليمي لطلاب كلية التربية جامعة الباحة لدى المفحوصين في الدراسة الحالية. إجراء تحليل تعليمي للمحتوىن: تم إجراء تحليل تعليمي لمحتوى المقرر وفقاً لمجالات الأهداف في تصنيف روبرت جانييه وهي معلومات لفظية، مهارات عقلية، استراتيجيات معرفية، مهارات نفسحركية، اتجاهات. لم تتضمن الدراسة الأهداف في المجال النفسحركي لارتباط تقويمها بمقاييس التقدير لتقويم المنتج المتمثل في مشروع التصميم الذي يكتمل إعداده من قبل الطلاب بعد استكمال

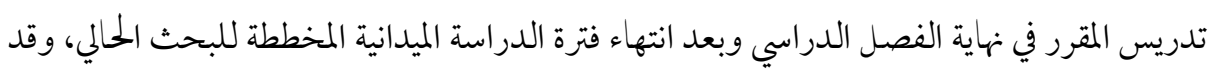
اشتمل الاختبار علن المعلومات النظرية للتصميم التعليمي وبعض المكونات المعرفية للمهارات النفسحركية. كما لم تتضمن الدراسة تقويم الأهداف الوجدانية للمقرر. بناء جدول مواصفات: تم بناء جدول مواصفات للربط بين الأهداف الإجرائية ومحاور المحتوئ الدراسي، وتحديد عدد المفردات اللازمة لكل هدف في الاختبار ـ وفقاً لتصيف جانييه كتابة فقرات الاختبار: تم صياغة مفردات الاختبار علن نمط الاختيار من متعدد. اشتمل الاختبار في صورته الأولية علن عدد 30 مفردة، يتكون كل سؤال من جذر السؤال وأربعة بدائل تتضمن إجابة صحيحة واحدة. يعطى كل سؤال درجة لإجابة الصحيحة وصفر للإجابة الخطأ، وعليه

$$
\text { تراوحت درجات الاختبار بين (صفر -30) درجة. }
$$

كتابة الإرشادات وإعداد مفتاح الإجابة وطباعة النسخة الأولية للاختبار. التحكيم: تم عرض الاختبار في صورته الأولية مطبو عاً علن عددمن المحكمين المختصين. وتم

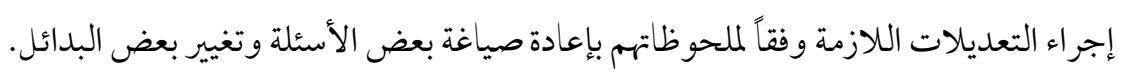
التطبيق الاستطلاعي للاختبار: تم تطبيق الاختبار على مجموعة استطلاعية من 12 طالباًتم اختيارها من طلاب السنة الرابعة من طلاب التربية النظاميين للتحقق من وضوح الأسئلة والتعليات، 
وتقدير زمن الاختبار، واستخر اج معاملات الصدق والثبات للاختبار، ومعاملات الصعوبة والتمييز

$$
\text { لفقرات الاختبار . تم التحقق من وضوح الاختبار، ويلغ زمن الاختبار } 40 \text { دقيقة. }
$$

حساب معاملات الصعوبة والتمييز لمفردات الاختبار : الجلدول 2 التالي يوضح قيم معاملات

الصعوبة ومعاملات التمييز لمفردات اختبار التحصيل.

وقد تراوحت معاملات الصعوبة بين (84.- 16.)، ومعاملات التمييز بين (5.- 4.) وهي

مناسبة.

جدول 2معاملات والصعوبة والتمييز لمفردات اختبار التحصيل

\begin{tabular}{|c|c|c|c|c|c|c|c|c|c|}
\hline معامل التمييز & الصعوبة & $(\dot{\tau})$ & (ص) & السؤال & التمييز & معامل & $(\dot{\tau})$ & (صى) & رقالم \\
\hline 0.5 & 0.66 & 8 & 4 & 16 & 0.5 & 0.34 & 4 & 8 & 1 \\
\hline 0.5 & 0.50 & 6 & 6 & 17 & 0.5 & 0.66 & 8 & 4 & 2 \\
\hline 0.4 & 0.16 & 2 & 10 & 18 & 0.5 & 0.50 & 6 & 6 & 3 \\
\hline 0.5 & 0.50 & 6 & 6 & 19 & 0.5 & 0.50 & 6 & 6 & 4 \\
\hline 0.5 & 0.66 & 8 & 4 & 20 & 0.4 & 0.84 & 10 & 2 & 5 \\
\hline 0.5 & 0.34 & 4 & 8 & 21 & 0.5 & 0.66 & 8 & 4 & 6 \\
\hline 0.4 & 0.16 & 2 & 10 & 22 & 0.5 & 0.50 & 6 & 6 & 7 \\
\hline 0.5 & 0.34 & 4 & 8 & 23 & 0.5 & 0.34 & 4 & 8 & 8 \\
\hline 0.5 & 0.66 & 8 & 4 & 24 & 0.5 & 0.34 & 4 & 8 & 9 \\
\hline 0.4 & 0.16 & 2 & 10 & 25 & 0.5 & 0.50 & 6 & 6 & 10 \\
\hline 0.5 & 0.50 & 6 & 6 & 26 & 0.5 & 0.50 & 6 & 6 & 11 \\
\hline 0.4 & 0.84 & 10 & 2 & 27 & 0.5 & 0.34 & 4 & 8 & 12 \\
\hline 0.4 & 0.16 & 2 & 10 & 28 & 0.4 & 0.16 & 2 & 10 & 13 \\
\hline 0.5 & 0.34 & 4 & 8 & 29 & 0.4 & 0.84 & 10 & 2 & 14 \\
\hline 0.5 & 0.50 & 6 & 6 & 30 & 0.5 & 0.50 & 6 & 6 & 15 \\
\hline \multicolumn{10}{|c|}{ (ص)= عدد الإجابات الصحيحة، (خ)= عدد الإجابات الخطأ } \\
\hline
\end{tabular}

http://dx.doi.org/10.29009/ijres.5.1.4 
معامل التمييز=معامل السهولة × معامل الصعوبة (الكناني، عيسى، 1992، 161) معامل ثبات الاختبار: بناءً على نتائج التطبيق الاستطلاعي تم حساب معامل الثبات بطريقة التجزئة النصفية واستخدام معادلة كرنباخ ألفا، وبلغ معامل الثبات.87

معامل صدق الاختبار : تم بناء علن معامل الثبات تم حساب معامل الصدق الذاتي وقد بلغ.93 الصورة النهائية للاختبار: تم إصدار الاختبار بشكله النهائي بعدد 30 فقرة، وتم تصميم الاختبار إلكترونيا باستخدام برنامج Wondershare Quiz Creator (4.5 وتم رفعه إلى جدولة المقرر الإلكتروني في نظام MOODLE LMS قبل بداية الدراسة الميدانية. ثانياً: مقياس الر ضاعن بيئة التعلم: تم إعدادمقياس الر ضا عن بيئة التعلم المدمج بوا سطة الباحث، وذلك في ضوء الإطار النظري للبحث، وبعض الأبعاد التي تضمنتها بعض المقاييس السابقة للر ضا عن بيئة التعلم، وتم استخراج دلالات الصدق والموثوقية للمقياس قبل استخدامه. ثالثاً: مقياس التنظيم الذاتي للمتعلم: بعد الرجوع علن عدد من نماذج واستراتيجيات ومقاييس التنظيم

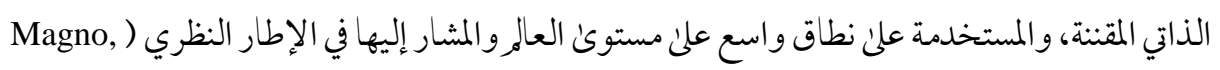
2010, Pintrich, 2000 قام الباحث بإعداد وتحكيم مقياس للتنظيم الذاتي للتعلم، وتم تحكيمه واستخراج دلالات الصدق والثبات بالتطبيق علئ مجموعة استطلاعية مكونة من عدد 115 طالب تم اختيارهم بشكل عشوائي من طلاب كلية التربية جامعة الباحة النظاميين. اشتمل المقياس بصورته النهائية علن عدد 55 فقرة موزعة في عدد سبعة محاور وهي: المحور الأول: استراتيجيات الذاكرة Memory Strategies (14 عبارة) المحور الثاني: وضع وتخطيط الأهداف Goal Setting (5 عبارات) المحور الثالث: التقويم الذاتي أو تطوير الذات Self-Evaluation (12 عبارة) المحور الرابع: طلب المساعدة Seeking Assistance (8 عبارات) 
المحور الخامس: بنية البيئة Environmental Structure (5 عبارات) المحور السادس:مسئولية التعلم Learning Responsibility عبارات) (6)Organizing (المحور السابع: التنظيم (6بارات) تم استخدام التدرج الخماسي لتقدير استجابات المفحوصين عن عبارات المقياس وهي: مو افق بقوة (5درجات)، موافق (4درجات)، محايد (3درجات)، غير موافق (درجتان)، غير موافق مطلقاً (درجة واحدة). وعليه صارت الدرجة الدنيا للمقياس 55درجة، والدرجة القصوي 275درجة. بعد رصد درجات المفحوصين

\section{تطوير مواد المعالجة التجريبية}

تم تصميم مقرر إلكتروني في مقرر التصميم التعليمي بثلاث أنماط نختلفة من نظم الإبحار؛ هي

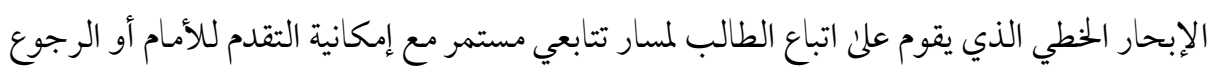
إلى الخلف للمراجعة من خلال أزرار (التالي) و(رجوع)، ونمط الإبحار الشبكي حيث تتاح للمتعلم كافة مكونات البنية العامة للمقرر وتتاح للمتعلم إمكانية التنقل العشوائي وفقاً لقرار اته. ونمط الإبحار الهرمي (الهيراركي Hierarchy) وهو نمط هجين بين الإبحار الخطي والشبكي قائمة علن التسلسل المنطقي للمقرر. تم تصميم المقرر باستخدام برنامج (Articulate Storyline 2.0)، وتم تصدير المشروع بتنسيق (Tin Can API)، كما تم رفع حزمة المقرر الإلكتروني على الإنترنت عبر نظام إدارة

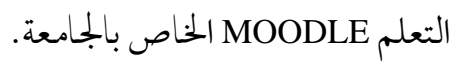

تم تصميم المقرر الإلكتروني باتباع الإجراءات نموذج التصميم المنظم للتعليم لوولتر ديك ولو كيري (ديك، وكاري، 2000) والذي يعد من أكثر نماذج التصميم التعليمي شيوعا واستخداما، 
لوضوح وسهولة تطبيقه، كا تم توظيف بعض المبادئ المشتقة من النحاذج الأخرى في بعض الإجراءات. وبصفة عامة تم التصميم والتطوير بالخطوات التالية: 1. تحديد الأهداف التعليمية العامة للمقرر.

$$
\begin{aligned}
& \text { 2. إجراء التحليل التعليمي للأهداف العامة. } \\
& \text { 3. تحليل المتعلمين والسياق. } \\
& \text { 4. كتابة أهداف الأداء. } \\
& \text { 5. تطوير مقايس التقدير. }
\end{aligned}
$$$$
\text { 6. - تصميم الاستراتيجية التعليمية. }
$$$$
\text { 7. تطوير المواد التعليمية. }
$$$$
\text { 8. - ت تصميم الثفاعلات ونظم الإبحار. }
$$

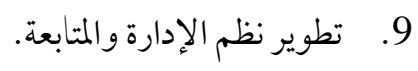

10. تصميم التقويم البنائي والمراجعة التعليمية.

$$
\text { 11. إنتاج المشروع بشكله النهائي. }
$$

\section{تطبيق الدراسة الاستطلاعية}

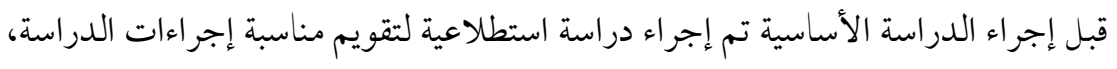

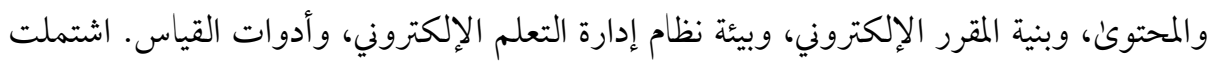

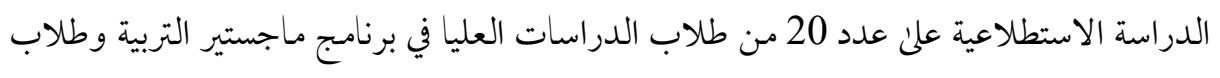

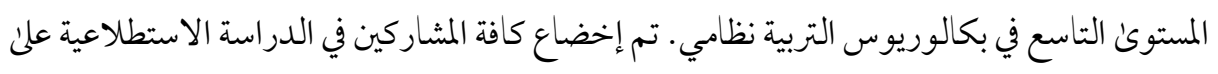

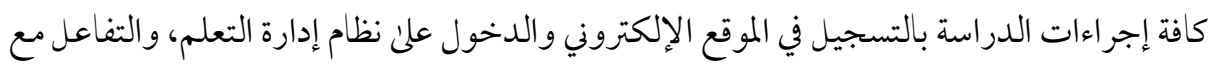


المواد التعليمية في المقرر وأداء الاختبارات والمقاييس المثلقة بالدراسة. تم الحصول علن التغذية الراجعة

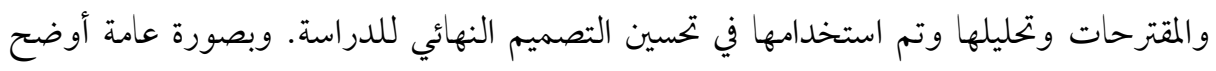

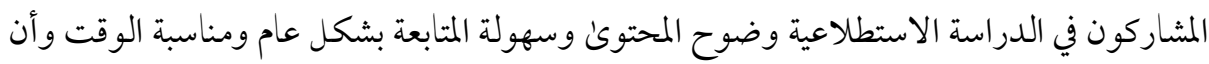

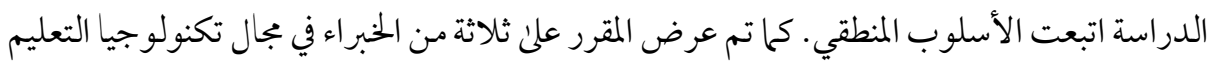
للتحكيم وتم إجراء التعديلات اللازمة بناء علن مقتر حاتهم.

\section{تطبيق الدراسة الميدانية}

بدأت الدراسة التجريبة في الفصل الثاني من العام الدراسي 2018-2019م. تم تنفيذ إجراءات الدراسة عبر نظام إدارة التعلم الإلكتروني. بداية قام الباحث بتسجيل الدخول علن النظام

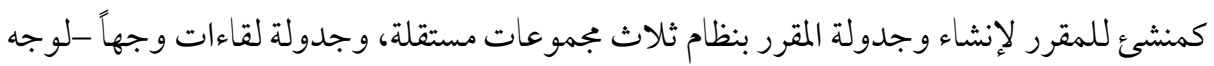

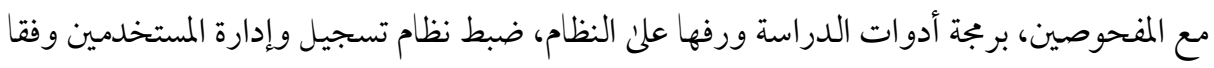
لمتغيرات الدراسة. وعلن كل أفراد العينة التسجيل في النظام وملاً البيانات الديمغرافية، وتنفيذمقياس التراس

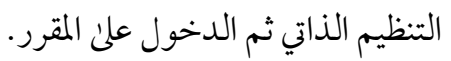

يتولم نظام إدارة التعلم الإلكتروني آليا توزيع المفحوصين بالطريقة العشوائية علن مجموعات

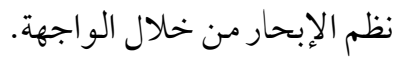

بعد أداء المفحوصين لمقياس التنظيم الذاتي يطلب منهم التفاعل مع المقرر وتنفيذ كافة الأنشطة والفعاليات التي يتضمنها المقرر. بعد انتهاء الطالب من دراسة المقرر يتم توجيهه آلياً للإجابة عن الاختبار البعدي، ومن ثم الإجابة عن مقياس الرضاعن بيئة التعلم. تككن جميع المفحوصين من إتمام دراسة المقرر في الزمن المحدد. 
تصنيف المفحوصين وفقاً لمستوى التنظيم الذاتي للتعلم

تم استخدام مقياس التنظيم الذاتي الذي تم تقنينه في الدراسة الحالية. تم عرض المقياس علن المفحوصين وتسجيل وتحليل النتائج لتحديد مستوى التنظيم الذاتي لكل طالب. الدرجة الدنيا للمقياس 55درجة والدرجة القصوئ 275درجة. تراوحت درجات أفراد العينة على المقياس بين 90درجة و 250درجة، المدئ بالنسبة لدرجات المفحوصين تراوح بين 80 و 265 درجة. وبلغ متوسط الدرجات 153 والانحراف المعياري 81.5. وتم تصنيف الحاصلين تقدير أعلى من المتوسط بنصف الانحراف المعياري أو أكثر مرتفعي التنظيم الذاتي، والحاصلين علن تقدير أقل من المتوسط بنصف الانحراف المعياري أو أقل ضعيفي التنظيم الذاتي، واللذين يجصلون على تقدير حول المتوسط بها لا لا يزيد أو يقل عن نصف الانحر اف المعياري في فئة التنظيم الذاتي المتوسط. من بين 219 مفحوصاً 63 مرتفعي التنظيم الذاتي، و63 متوسطي التنظيم الذاتي، و93 ضعيفي التنظيم الذاتي. الجدول التالي يوضح توزيع المفحوصين وفقاً لمتغيرات الدراسة.

جدول 3 توزيع المفحوصين علن مجموعات المعالجة التجريبية

\begin{tabular}{|c|c|c|c|c|}
\hline \multicolumn{5}{|c|}{$\begin{array}{c}\text { (نظم الإبحار في المقرر الإلكتروني) } \\
\text { (المعالجة التجريبة }\end{array}$} \\
\hline المجموع & إبحار هرمي & إبحار شبكي & إبحار خطي & مهارات التظيم \\
\hline 63 & 26 & 15 & 22 & تنظيم ذاتي مرتفع \\
\hline 63 & 21 & 19 & 23 & تنظيم ذاتي متوسط \\
\hline 93 & 32 & 34 & 27 & تنظيم ذاتي ضعيف \\
\hline 219 & 79 & 68 & 72 & المجموع \\
\hline
\end{tabular}




\section{المعالجات الإحصائية}

تكونت البيانات في الدراسة الحالية من درجات مقياس التنظيم الذاتي للمتعلم، ودرجات الاختبار التحصيلي، ودرجات مقياس الرضاعن بيئة التعلم. تم تسجيل بيانات المتغيرات التابعة آلياً في قاعدة البيانات. أما بيانات المفحوصين حول مقياس التنظيم الذاتي للتعلم تم رصدها بواسطة الباحث وتم إدخاها يدوياً إلى قاعدة البيانات. بناءً علن درجات مقياس التنظيم الذاتي تم تصنيف المفحوصين إلى ثلاث بجموعات (مرتفع، ومتوسط، وضعيف) التنظيم الذاتي للتعلم. كافة البيانات تم إدراجها في برنامج SPSS لإجر اء عمليات التحليل الإحصائي. نتائج الدراسة

تم أولاً إجراء التحليل الإحصائي الوصفي للبيانات باستخراج المتوسطات والانحرافات المعيارية للحصول علن المعلومات العامة، ولوصف واستخلاص خصائص المفحوصين، ثم تم إجراء التحليل الإحصائي الاستدلالي لدرجات اختبار التحصيل الدراسي ومقياس الرضا عن بيئة التعلم بناء علن بنية الإبحار في المقرر الإلكتروني (خطي، شبكي، هرمي)، ومستوكي التنظيم الذاتي للتعلم (مرتفع، 3x3 Factorial One-) متوسط، ضعيف) باستخدام التحليل العاملي 3*3 للتباين أحادي الاتجاه Way ANOVA والتنظيم الذاتي، والتفاعل بينها على كل من التعلم، والرضا. تم ضبط مستوى الدلالة (alpha level) في كامل التحليل الإحصائي عند.05 أي (ps.05). و وفيما يلي نتائج اختبار فرضيات الدراسة:

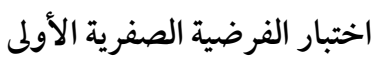

تنص الفرضية الصفرية الأولنى علن أنه: لا توجد فروق ذات دلالة إحصائية عند مستوى دلالة معنوية (a=.05) بين متوسطات درجات الطلاب في اختبار التصميم التعليمي تعزئ لنمط الإبحار في المقرر الإلكتروني لدئ طلاب البكالوريوس بكلية التربية. 
لاختبار الفرضية الصفرية الأولن تم حساب المتوسطات والانحرافات المعيارية لدرجات

المفحوصين في اختبار التحصيل الدراسي البعدي، الجدول 4 التالي يوضح الإحصاء الوصفي لدرجات اختبار التحصيل الدراسي.

$$
\text { جدول } 4 \text { المتوسطات والانحرافات المعيارية لتتائج اختبار التحصيل الدراسي البعدي }
$$

\begin{tabular}{|c|c|c|c|c|c|}
\hline \multicolumn{6}{|c|}{ مستوى النظيم الذاتي } \\
\hline المجموع & تنظيم ذاتي مرتفع & تنظيم ذاتي متوسط & تنظيم ذاتي ضعيف & \multicolumn{2}{|c|}{ نمط الإبحار في المقرر } \\
\hline 19.53 & 24.15 & 18.13 & 15.32 & $\mathrm{M}$ & \multirow{3}{*}{ إبحار خطي } \\
\hline 8.32 & 8.54 & 7.46 & 6.10 & SD & \\
\hline 72 & 27 & 23 & 22 & $\mathrm{n}$ & \\
\hline 19.40 & 22.06 & 17.42 & 15.87 & M & \multirow{3}{*}{ إبحار شبكي } \\
\hline 7.88 & 8.03 & 7.54 & 6.06 & SD & \\
\hline 68 & 34 & 19 & 15 & $\mathrm{n}$ & \\
\hline 18.01 & 18.31 & 20.10 & 15.96 & M & \multirow{3}{*}{ إبحار هرمي } \\
\hline 6.53 & 6.24 & 7.15 & 5.97 & SD & \\
\hline 79 & 32 & 21 & 26 & $\mathrm{n}$ & \\
\hline 18.94 & 21.38 & 18.57 & 15.71 & M & \multirow{3}{*}{ المجموع } \\
\hline 7.58 & 7.91 & 7.35 & 5.94 & SD & \\
\hline 219 & 93 & 63 & 63 & $\mathrm{n}$ & \\
\hline
\end{tabular}

$$
\text { المتوسط= M= الانحر اف المعياري=SD، العددي }
$$

يتضح من الجدول أعلاه أن متو سط درجات المفحوصين في اختبار التحصيل لمجموعة الإبحار الخطي (M=19.53, SD=8.32) أكبر من متوسط درجات التحصيل لمجموعة الإبحار الشبكي

$$
\text { (M=18.94, SD=7.58)، والإبحار الهرمي (M=19.40, SD=7.88) }
$$

للكشف عن دلالة الفروق بين المتوسطات تم تطبيق تحليل التباين. وكشفت نتائج التحليل العاملي للتباين أن قيمة (ف) بالنسبة للفروق بين متوسطات درجات التحصيل ليست ذات دلالة

$$
\text { F (2.210)=.436, p>.05 إحصائية }
$$

عليه يتم قبول الفرضية الصفرية الأولن بعدم وجود فروق التحصيل تعزىن لنمط الإبحار. http://dx.doi.org/10.29009/ijres.5.1.4 
عليه فإن اختلاف بنية الإبحار في المقرر الإلكتروني (خطي، شبكي، هرمي) لا يؤثر في درجات التحصيل الدراسي.

\section{اختبار الفرضية الصفرية الثانية}

تنص الفرضية الثانية علن أنه: لا توجد فروق ذات دلالة إحصائية عند مستوى دلالة معنوية (a=05) بين متوسطات درجات الطلاب في مقياس الرضا عن بيئة التعلم تعزىن لنمط الإبحار في المقرر الإلكتروني لدئ طلاب البكالوريوس بكلية التربية.

لاختبار الفرضية الصفرية الثانية تم حساب المتوسطات والانحرافات المعيارية لدرجات

المفحوصين في مقياس الرضا عن بيئة التعلم، الجمدول 5 التالي يوضح الإحصاء الوصفي لدرجات مقياس الرضا.

$$
\text { جدول } 5 \text { المتوسطات والانحر افات المعيارية لتتائج مقياس الرضا عن بيئة التعلم }
$$

\begin{tabular}{|c|c|c|c|c|c|}
\hline المجموع & تنظيم مرتفع & تنظيم متوسط & تنظيم ضعيف & & نمط الإبحا \\
\hline 10.58 & 12.33 & 9.91 & 9.14 & $\mathrm{M}$ & \multirow{3}{*}{ إبحار خطي } \\
\hline 4.17 & 4.03 & 4.35 & 3.51 & SD & \\
\hline 72 & 27 & 23 & 22 & $\mathrm{n}$ & \\
\hline 10.90 & 12.03 & 10.05 & 9.40 & $\mathrm{M}$ & \multirow{3}{*}{ إبحار شبكي } \\
\hline 4.14 & 4.31 & 3.24 & 4.29 & SD & \\
\hline 68 & 34 & 19 & 15 & $\mathrm{n}$ & \\
\hline 10.00 & 10.16 & 11.00 & 9.00 & M & \multirow{3}{*}{ إبحار هرمي } \\
\hline 3.66 & 3.84 & 3.55 & 3.39 & SD & \\
\hline 79 & 32 & 21 & 26 & $\mathrm{n}$ & \\
\hline 10.47 & 11.47 & 10.32 & 9.14 & M & \multirow{3}{*}{ المجموع } \\
\hline 3.98 & 4.14 & 3.75 & 3.60 & SD & \\
\hline 219 & 93 & 63 & 63 & $\mathrm{n}$ & \\
\hline
\end{tabular}

$$
\text { المتوسط=M، الانحر اف المعياري=SD، العددي }
$$

http://dx.doi.org/10.29009/ijres.5.1.4 
يتضح من الجدول أعلاه أن متو سط درجات مقياس الرضا عن بيئة التعلم لمجموعة الإبحار ألمار

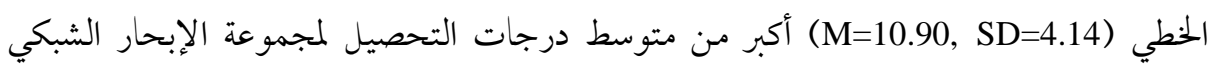
(M=10.00, SD=3.66)، والإبحار الهرمي (M=10.58, SD=4.17)

للكشف عن دلالة الفروق بين المتوسطات تم استخدام تحليل التباين. كشفت نتائج التحليل العاملي للتباين أن قيمة (ف) بالنسبة للفروق بين متوسطات درجات التحصيل ليست ذات دلاتلائل إحصائية

عليه يتم قبول الفرضية الصفرية الثانية بعدم وجود في الرضا تعزئ لنمط الإبحار. وعليه فإن اختلاف بنية الإبحار في المقرر الإلكتروني (خطي، شبكي، هرمي) لا يؤثر في درجات مستوئ الرضا عن بيئة التعلم لدئ المفحوصين.

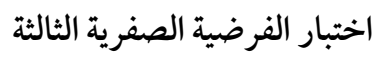

تنص الفرضية الصفرية الثالثة علئ أنه: لا توجد فروق ذات دلالة إحصائية عند مستوى دلالة معنوية (05=05) بين متوسطات درجات الطلاب في اختبار التصميم التعليمي تعزى لمستوىن التنظيم الذاتي للتعلم لدئ طلاب البكالوريوس بكلية التربية.

يتضح من الجدول 3 أن متوسط درجات المفحوصين في اختبار التحصيل (21.38) بالنسبة للطلاب ذوي التنظيم الذاتي المرتفع أكبر من متوسط درجات التحصيل للطلاب ذوي دري التنظيم الذاتي

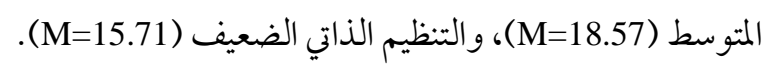

$$
\mathrm{M}=21.38), \mathrm{F}(2,210)=12.145, \mathrm{p}<.05
$$

للكشف عن دلالة الفروق بين متوسطات درجات التحصيل، بالنسبة لمتغير التنظيم الذاتي للتعلم تم استخدام تحليل التباين أحادي الاتجاه. وكشفت نتائج التحليل العاملي للتباين عن دلالة دئل الفروق بين متوسطات درجات المفحوصين في اختبار التحصيل تعزي لمستون التنظيم الذاتي $F(2.210)=12.145, p<.05$ 
وعليه يتم رفض الفرضية الصفرية الثالثة للبحث، وقبول الفرضية البديلة بوجود فروق في التحصيل تعزى لمستوى التنظيم الذاتي. وعليه فإن مستوى التنظيم الذاتي للتعلم يؤثر في درجات التحصيل الدراسي. وللكشف عن وجهة الفروق وتحديد أي مستويات التنظيم الذاتي يختلف. تم إجراء مقارنات بعدية متعددة Post Hoc لكل متغير تابع. يتم إجراء المقارنات البعدية المتعددة إما باستخدام مقياس توكي (Tukey Test) أو مقياس قيم هاولز (Games-Howell) اعتماداً على تجانس أو عدم تجانس التباين في اختبار ليفين ( Levene's (statistic . و الجمدول 6 يوضح نتائج اختبار ليفين بالنسبة لمتغير التحصيل الدراسي، جدول 6 اختبار ليفين لتجانس التباين

\begin{tabular}{|c|c|c|c|c|}
\hline df2 & df1 & Sig. & Levene's Statistic & المتغيرات التابعة \\
\hline 216 & 2 & .004 & 5.798 & اختبار التحصيل \\
\hline
\end{tabular}

بما أنه قد تحقق تجانس التباين بالنسبة للتحصيل الدراسي في اختبار ليفين، تم استخدام مقياس Games-Howell للمقارنات البعدية عن وجود فروق دالة إحصائياً في متوسط درجات التحصيل لصالح التنظيم الذاتي

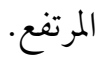
عليه كلما زاد مستوى التنظيم الذاتي للمتعلم يزداد تحصيله الدراسي. الفرضية البديلة الثالثة: توجد فروق ذات دلالة إحصائية عند مستوىن دلالة معنوية (05.=م) بين متوسطات درجات الطلاب في اختبار التصميم التعليمي تعزى لمستوى التنظيم الذاتي للتعلم لدىن طلاب البكالوريوس بكلية التربية لصالح التنظم الذاتي المرتفع. 


\section{اختبار الفرضية الصفرية الرابعة}

تنص الفرضية الصفرية الثالثة علن أنه: لا تو جد فروق ذات دلالة إحصائية عند مستوى دلالة معنوية (a=05) بين متوسطات درجات الطلاب في مقياس الرضا عن بيئة التعلم تعزى لمستوىن التنظيم الذاتي للتعلم لدئ طلاب البكالوريوس بكلية التربية.

يتضح من الجدول 3 أن متوسط درجات المفحوصين في اختبار التحصيل (21.38) بالنسبة للطلاب ذوي التنظيم الذاتي المرتفع أكبر من متوسط درجات التحصيل للطلاب ذوي التنيم الذاتي المتوسط (M=18.57)، و التنظيم الذاتي الضعيف (M=15.71).

$$
\mathrm{M}=21.38), \mathrm{F}(2,210)=12.145, \mathrm{p}<.05
$$

للكشف عن دلالة الفروق بين متوسطات درجات التحصيل، بالنسبة لمتغير التنظيم الذاتي للتعلم تم استخدام تحليل التباين أحادي الاتجاه. وكشفت نتائج التحليل العاملي للتباين عن دلالة الفروق بين متوسطات درجات المفحوصين في اختبار التحصيل تعزي لمستون التنظيم الذاتي $\mathrm{F}(2.210)=12.145, \mathrm{p}<.05$

وعليه تم رفض الفرضية الصفرية الرابعة للبحث وقبول الفرضية البديلة بوجود فروق في درجات الرضا تعزئ لمستوئ التنظيم الذاتي. وعليه فإن مستوى التنظيم الذاتي للتعلم يؤثر في درجات الرضاعن بيئة التعلم. - م.

للكشف عن وجهة الفروق تم تطبيق اختبار ليفين لتجانس التباين. و الجمدول 6 يوضح اختبار جدول 7 اختبار ليفين لتجانس التباين

\begin{tabular}{|c|c|c|c|c|}
\hline df2 & df1 & Sig. & Levene's statistic & المتغيرات التابعة \\
\hline 216 & 2 & .105 & 2.277 & مقياس الرضا \\
\hline
\end{tabular}

بما أنه لميتحقق تجانس التباين بالنسبة لمقياس الرضا عن بيئة التعلم في اختبار ليفين، تم استخدام مقياس Tukey لإجراء المقارنات البعدية لتحليل متوسطات المجموعات. وقد كشفت نتائج التحليل 
عن وجود فروق دالة إحصائياً في متوسط درجات مقياس الرضا عن بيئة التعلم لصالح التنظيم الذاتي

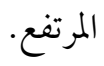
جدول 8 نتائج مقياس توكي Tukey

\begin{tabular}{|c|c|c|c|c|c|}
\hline Sig & $\mathbf{F}$ & Mean Square & df درجات الحرية & مجموع المربعات & \\
\hline \multirow[t]{3}{*}{.091} & 2.475 & 101.671 & 2 & 203.341 & المجموعات \\
\hline & & 41.074 & 76 & 3121.646 & المجموعات \\
\hline & & & 78 & 3324.987 & المجموع \\
\hline
\end{tabular}

اختبار الفرضية الصفرية الخامسة

تنص الفرضية الصفرية الخامسة علن أنه: لا توجد فروق ذات دلالة إحصائية عند مستوى دلالة معنوية (a=05) بين متوسطات درجات الطلاب في اختبار التصميم التعليمي تعزى للتفاعل بين نمط الإبحار في المقرر الإلكتروني ومستوى التنظيم الذاتي للتعلم لدىن طلاب البكالوريوس بكلية التربية. التفاعل يعني أن أثر أحد المتغيرات يعتمد علئ مستوني المتغير الآخر (Howell,2002,p40). F(4,210)=2.547, p<.05 اختبار الفرضية الصفرية الخامسة تم استخدام تحليل التباين.. فقد كشفت نتائج الدراسة عن وجود أثر للتفاعل بين بنية الإبحار في المقرر الإلكتروني، ومستوى التنظيم الذاتي للتعلم علن التحصيل الدراسي

\section{اختبار الفرضية الصفرية السادسة}

تنص الفرضية الصفرية السادسة علئ أنه: لا توجد فروق ذات دلالة إحصائية عند مستوىن دلالة معنوية (a=.05) بين متو سطات درجات الطلاب في مقياس الرضا عن بيئة التعلم تعزىن للتفاعل 
بين نمط الإبحار في المقرر الإلكتروني ومستوي التنظيم الذاتي للتعلم لدن طلاب البكالوريوس بكلية التربية.

F(4,210)=1.373, p<.05 اختبار الفرضية الصفرية السادسة تم استخدام تحليل التباين كشفت نتائج الدراسة عن عدم وجود أثر للتفاعل بين بنية الإبحار في المقر الإكتروني، ومستوى التنظيم الذات للتعلم علن الرضا عن بيئة التعلم

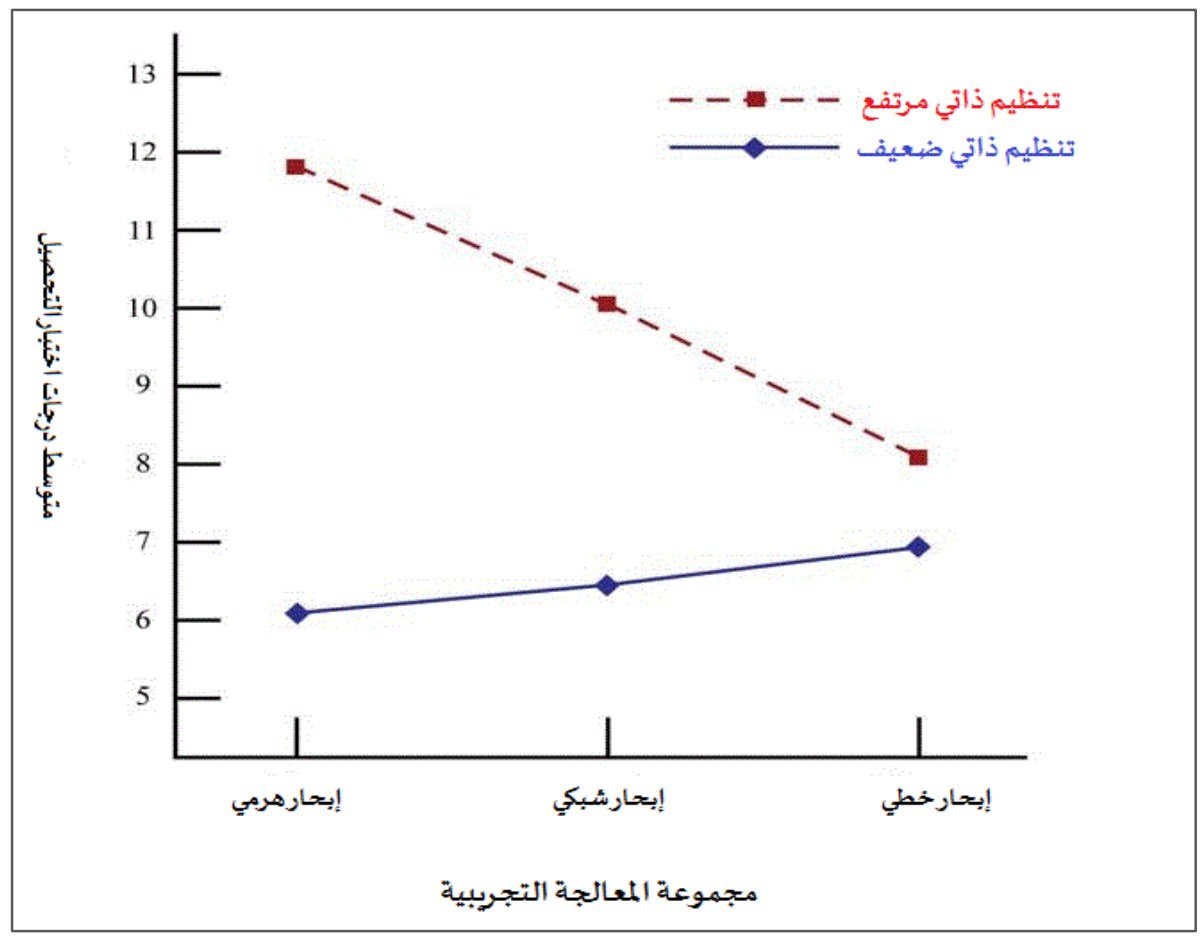

شكل 3يوضح التفاعل بين بنية الإبحار والتنظيم الذاتي

مناقشة النتائج

يمكن تلخيص النتائج التي تم التوصل إليها لاختبار فرضيات الدراسة باستخدام التحليل

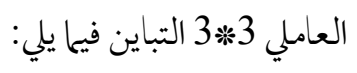

http://dx.doi.org/10.29009/ijres.5.1.4 
1. عدم وجود فروق ذات دلالة إحصائية بين متوسطات درجات التحصيل الدراسي بين

$$
\text { مجموعات الدراسة تعزئ لبنية الإبحار. }
$$

2. عدم وجود فروق ذات دلالة إحصائية بين متوسطات درجات مقياس الرضا بين مجموعات

$$
\text { الدراسة تعزئ لبنية الإبحار. }
$$

3. وجود فروق ذات دلالة إحصائية بين متوسطات درجات التحصيل الدراسي تعزئ للتنظيم

$$
\text { الذاتي لصالح التنظيم المرتفع. }
$$

4. وجود فروق ذات دلالة إحصائية بين متوسطات درجات مقياس الرضا للتنظيم الذاتي

$$
\text { لصالح التنظيم المرتفع. }
$$

وجود فروق ذات دلالة إحصائية في متوسط درجات اختبار التحصيل بين مجموعات

6. عدم وجود فروق ذات دلالة إحصائية في متوسط درجات مقياس الرضا عن بيئة التعلم بين بجموعات الدراسة تعزئ للتفاعل بين بنية الإبحار و التنظيم الذاتي للتعلم.

يتضح من نتيجة الفرضية الأولنا والثانية: أي أن أنماط الإبحار المستخدمة في الدراسة الحاليةله تؤثر في تعلم الطلاب، ولا في درجة الرضا عن بيئة التعلم لديهم. فعلن الرغم من دور نمط الإبحار في تيسير التصفح واختصار الوقت وبناء المفهوم، إلا أنه ربها تمكن المفحوصين في مجموعات المعالجة التجريبية المختلفة من الوصول إلى كافة الأنشطة والمصادر المطلوبة بصرف النظر عن نمط الإبحار المستخدم، وقد يرتبط ذلك بالطبيعة الإجرائية لمقرر التصميم التعليمي حيث يتعلم الطالب المبادئ النظرية في المقرر من أجل تنفيذها إجرائياً في مشروع التصميم. وكذلك عدم اشتمال المقرر الإلكتروني الحالي علن فعاليات خارج نظام ولا يحتاج الطالب للإبحار في الإنترنت خارج المقرر . تبين أن مع كفاية وقت التعلم لكل المجموعات. 
وعلن العموم فإن النتيجة تكثف عن عدم أهمية نظام الإبحار في حد ذاته إذا كان التصميم

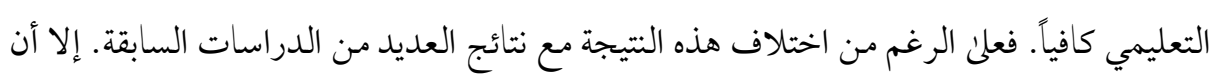

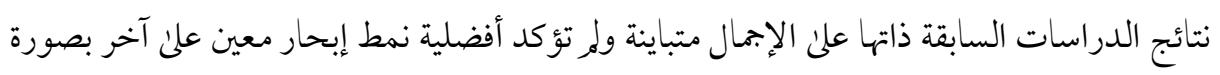

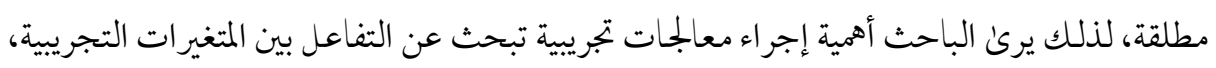

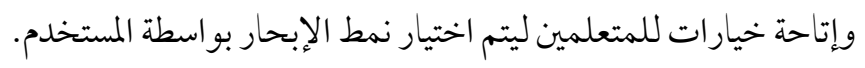

أما نتيجة الفرضية الثالثة والرابعة: فتؤكد أهمية مهارات التعلم المنظم ذاتياً، مع كافة المعالجات التجريبية. خاصة إن التعلم الإلكتروني يعتمد في الغالب علن التعلم بالخطو الذاتي، ويحتاج لدافعية ذاتية

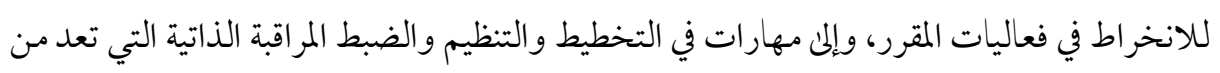

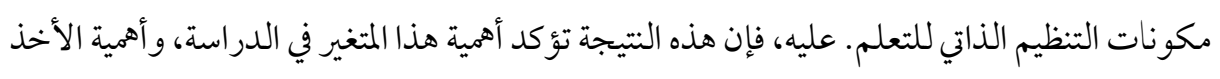

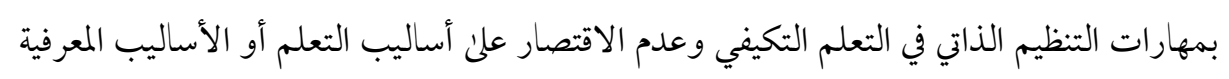
الأخرىن.

نتيجة الفرضية الخامسة والسادسة قد كشفت عن أثر التفاعل بين المتغيرات المستقلة وهي بنية

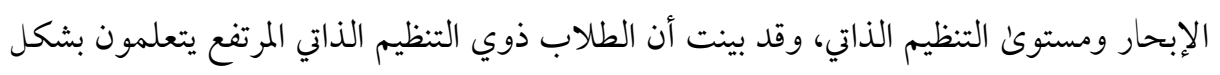

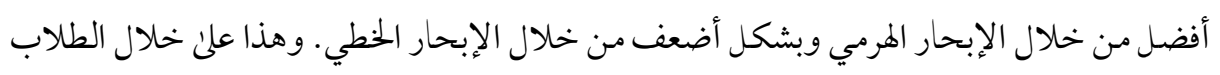

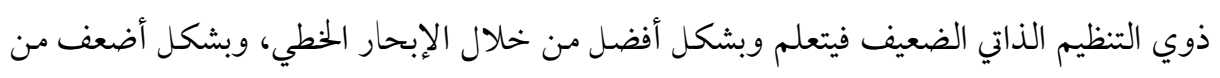

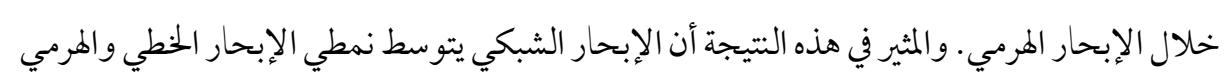

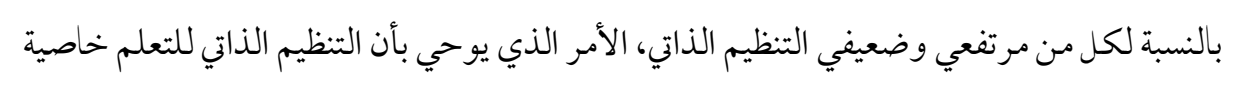

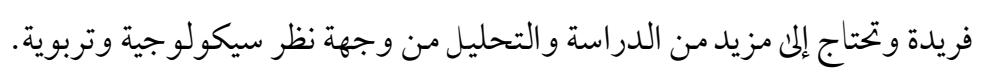
المحددات

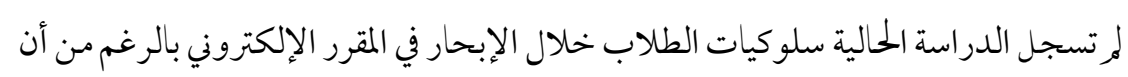

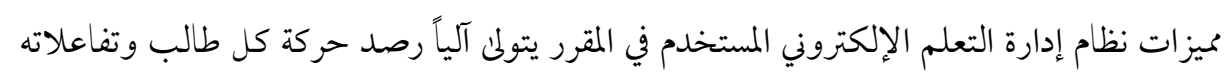


المختلفة مع النظام. ينبغي تحليل التسلسل الذي يتبه الطلاب في تفاعلهم مع المواد التعليمية. ويقترح الباحث أن يتم تسجيل سلوكيات الطلاب خلال الملاحة وفحصها وتحليلها في الدراسات المستقبلية. التباين الكبير بين المفحوصين في الدراسة الحالية في التخصص العلمي، والخبرات السابقة

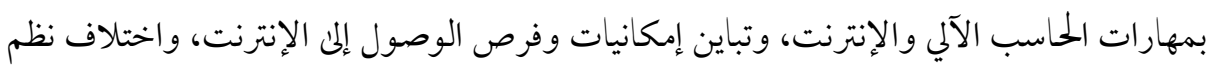

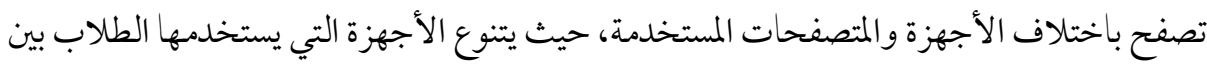

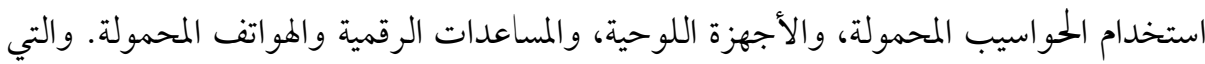

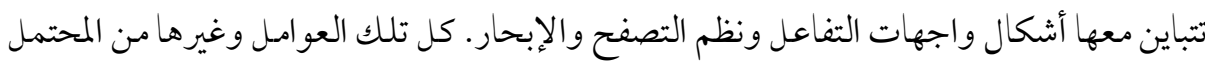
أن تؤثر في نتائج الدراسة الحالية.

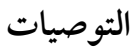

من خلال ما توصلت إليه الدراسة الحالية من نتائج، فإن الباحث يوصي با يلي:

1. الاهتحم بالتصميم المنهجي للمقرر الإلكتروني حيث إن من شأنها التأثير علن التحصيل والاحتفاظ أكثر من تأثير نظام الإبحار أو الملاحة.

2. الاهتمام بخصائص المتعلمين في مجال التصميم التعليمي وتوفير الثراء الذي يمكن كافة

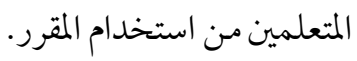

3. توفير خيارات وبدائل في نظم الإبحار، وفي المتغيرات الأخرى ما أمكن بحيث يستطيع المستخدم يختار بناءً علن خصائصه وتفضيلاته.

4. الاهتحام بطريقة بناء الروابط في المحتوئ الإلكتروني التعليمي لما ها من ميزات عديدة. 5. الاستفادة من نتائج الدراسة الحالية عند بناء الروابط في المحتويات التعليمية.

6. الدعوة إلى تصميم المقررات الإلكترونية في ضوء نظريات واضحة ومحددة لتحقيق أهداف تعلم أخرى وعدم الاقتصار علن التحصيل الدراسي. عن عملية التحصيل.

http://dx.doi.org/10.29009/ijres.5.1.4 
7. الاهتحام بإنتاج المحتويات الإلكترونية التعليمية وفق معايير تقنية محددة لتساعد علن تحقيق

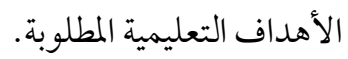

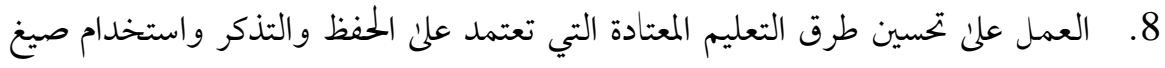
تعليمية جديدة مبتكرة تسهم في تحسين عملية التعلم.

9. تحقيق مبدأ التعلم الذاتي عند تصميم المحتوك الإلكتروني، حيث يقوم الطالب باختيار ما يرغب أن يتعلمه في الوقت الذي يريده وذلك وفق قدراته وإمكاناته.

استكمالاً لما بدأته الدراسة الحالية، فإن الباحث يقترح إجراء الدراسات التالية: 1. دراسة نظم الإبحار في بيئات التعلم الجديدة مثل التعلم من خلال الأجهزة المحمولة، والتعلم في بيئات التعلم الافتراضي والمعزز ودراسة متطلبات هذه النظم.

2. بدراسة أثر اختلاف الكيفية التي يتم بها بناء النصوص والروابط في المقرر الإلكتروني علن. تنمية مهارات التفكير المختلفة.

3. بحث أثر اختلاف الكيفية التي يتم بها تركيب النصوص والروابط في المقرر الإلكتروني علن.

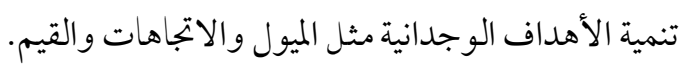

4. بحث أثر بُنى الروابط في المحتوى الإلكتروني في التحصيل الدراسي لمواد دراسية أخرىن. 5. بحث فاعلية بُنخ الروابط في المحتوى الإلكتروني وإحدنى استراتيجيات التفكير في تنمية التحصيل والتفكير للفئات الخاصة.

6. بحث فاعلية بُنى الروابط في المحتوى الإلكتروني علن تنمية المفاهيم المجردة للمتعلمين.

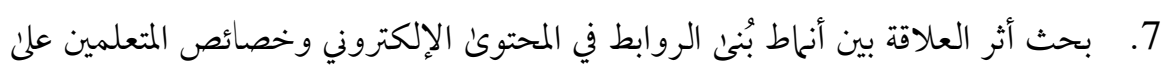
مخرجات التعلم في المواد الدراسية المختلفة. 8. تطبيق الدراسة الحالية في بيئات التعلم من خلال الأجهزة المحمولة. 
إبر اهيم، زينب ياسين حممد. (2013). فاعلية أدوات تقديم المحتوي القائمة علن تطبيقات التواصل

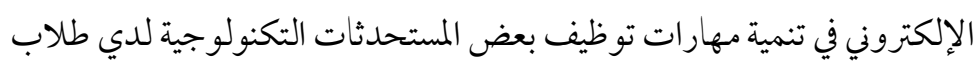

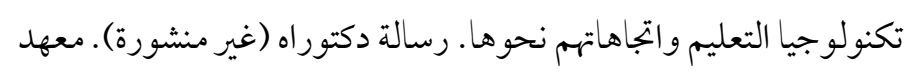

أبو حديد، فاطمة عبد السلام. (2004). تطوير منهج الرياضيات في ضوء المدخل المنظومي. المؤتمر

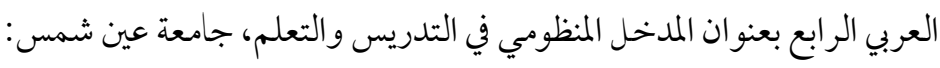

$$
\text { مركز تطوير العلوم، 3- } 4 \text { إبريل. }
$$

أيوب، علاء الدين عبد الحميد. (2011). نموذج الواحة الإثرائي وأثره علن القدرات التأملية

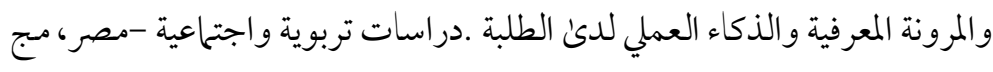

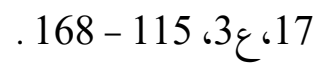

البهي، فؤاد. (1996). علم النفس الإحصائي وقياس العقل البشري. القاهرة: دار الفكر العربي. زيتون، حسن حسين. (2005). رؤية جديدة في التعليم -التِعليم الإلكتروني -المفهوم، القضايا، التطبيق، التقويم. الرياض: الدار الصولتية للتربية.

سرور، شياء عز العرب محمد. (2010). تصميم برنامج بنمطي الإبحار (الهرمي والشبكي) المفاهيم

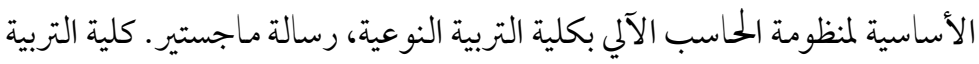

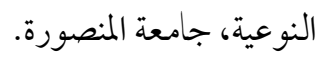

سرور، شياء عز العرب محمد. (2010). تصميم برنامج بنمطي الإبحار (الهرمي والشبكي) المفاهيم

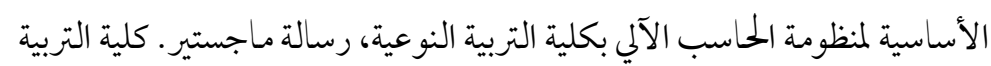

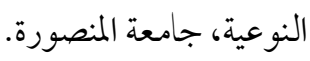


الصالح، بدر بن عبد الله. (2005). التعلم الإلكتروني والتصميم التعليمي: شراكة من أجل الجمودة. بحث مقدم للمؤتمر العاشر للجمعية المصرية لتكنولوجيا التعليم( تكنولوجيا التعليم الإلكتروني ومتطلبات الجودة الشاملة). القاهرة.

ماير (2004). التعلم بالوسائط المتعددة. ترجمة ليلن النابلسي. الرياض: مكتبة العبيكان محجوب، مصطفى محمد على. ( (2011). التفاعل بين أدوات الإبحار في برامج الكمبيوتر فائقة الوسائل ونمط التعليم وأثره على تنمية مهارات الطلاب في مقرر شبكات الحاسب. رسالة دكتوراه. كلية التربية، جامعة عين شمس.

محمد، شريف شعبان إبراهيم. (2010). أثر التفاعل بين نمط الإبحار والأسلوب المعرفي علئ تنمية مهارات تصميم مواقع الإنترنت التعليمية لدى طلاب قسم تكنولوجيا التعليم بكلية التربية النوعية جامعة بنها. رسالة ماجستير (غير منشورة). كلية التربية، جامعة بنها.

المزيد، محمد سليهان. (2011). أثر اختلاف أنحاط الإبحار في ألعاب الحاسب التعليمية على التحصيل

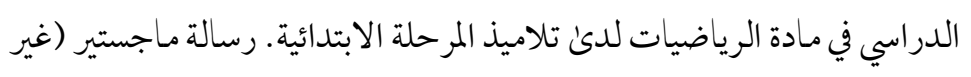
منشورة). كلية التربية، جامعة الملك عبد العزيز 


\section{References}

Bush, V. (1945, July). As we may think. Atlantic Monthly, 101-108. Conklin, J. (1987). Hypertext: An introduction and survey. IEEE Computer, 20(9), $17-41$.

Canas, J., Fajardo, I., Antoli, A. \& Salmeron, L., (2005). Cognitive inflexibility and the development and use of strategies for solving complex dynamic problems: effects of different types of training. Theoretical Issue in Ergonomics Science, 6(1), 95- 108.

Carmen, Z; Beatriz, B.; Stephan, S., (2004): Learning with hyperlinked Video-design criteria and efficient strategies for using audio video hypermedia. Learning and Instruction [on line], Available at: http://www.elsevier.com/locate/learninstruc.

Chen, C., \& Rada, R. (1996). Interacting with hypertext: A meta-analysis of experimental studies. Human-Computer Interaction, 11, 125-156.

Deak, O. (2003). The development of cognitive flexibility and language abilities. Advances in Child Development and Behavior, 31(1), 271- 327.

Dick, W., Carey, L., \& Carey, J. O. (2001). The systematic design of instruction (5th ed.). New York: Addition-Wesley Educational.

Dresel, M. \& Haugwitz, M. (2008). A computer-based approach to fostering motivation and self-regulated learning. Journal of Experimental Education, 77(1), 3-18.

Eveland, W. P., \& Dunwoody, S. (2001). User control and structural isomorphism or disorientation and cognitive load? Learning from web versus print. Communication Research, 28, 48-78.

Harris, J. \& Grantgenettm N. (1993). A Developmental sequence of children's Semantic relationships. Implications for design of interaction hypermedia materials. Journal of educational multimedia and hypermedia, 2(1), 83- 101.

Howell, D. C. (2002). Statistical methods for psychology (5th Ed.). Pacific Grove, CA: Wadsworth Group. 
Hsu, P. S., \& Dwyer, F. M. (2004). Effect of level of adjunct questions on achievement of field independent/field dependent learners. International Journal of Instructional Media, 31(1), 99-106.

Hsu, Y.-C. (2006). Better educational website interface design: The implications from gender-specific preferences in graduate students. British Journal of Educational Technology, 37(2), 232-242.

Jacobson, M. J. \& Spiro, R. J. (1995). Hypertext learning environments, cognitive flexibility, and the transfer of complex knowledge: An empirical investigation. Journal of Educational Computing Research, 12, 301333.

Jonassen, H. David. (1991). Hypertext as instructional design: Journal of Educational Technology research and Development, vol. 39(1), 83-92.

Lai-Lai, T., et al., (2003). I interacting with Hypertext: An Experimental Investigation of Navigation tools, Electronic commerce Research and Applications 2.

Magno, C. (2009). Assessing and developing self-regulated learning. The Assessment Handbook, 1, 26-42.

Martin, M., Anderson, C. \& Thweatt, K. (1998). Aggressive Communication Traits and Their Relationship with Cognitive Flexibility Scale. Journal of Social Behaviour \& Personality, 13(3), 531- 540.

McDonald, Sharon; Stevenson, Rosemary. (2007). Effects of text structure and prior knowledge of the learner on navigation in hypertext. Human Factors, 40(1), 1-18.

Murray, N. Hirt, E. \& Sujan, H. (1990). The Influence of Mood on Categorization: A Cognitive Flexibility Interpretation. Journal of Personality \& Social Psychology, 50(3), 411- 425.

Paul De Bra and Licia calive (1998). "An open adaptive Hypermedia Architecture:

Journal of Hyper media and multimedia, 4(2), 115- 159.

Pintrich, P. (2000). The Role of goal orientation in self-regulated learning. In M.

Boekaerts, P. Pintrich, \&M. Zeidner (Eds). Handbook of Self-

Regulation, (Pp.451-502). San Diego., Academic Press. 
Pintrich, P. (2004). A conceptual framework for assessing motivation and selfregulated learning in college students. Educational Psychology Review, 16(4), 385-407.

Puntambekar, Sa.; Goldstein, J. (2007). Effect of Visual Representation of the Conceptual Structure of the Domain on Science Learning and Navigation in a Hypertext Environment. Journal of Educational Multimedia and Hypermedia. Volume16,Issue4,P429-459.

Rand, J. S., \& pull, J. Feltovich \& Michael, J. Jacobson and Richard, L. Coulson. (1991). Flexibility constructivism, and hypertext: Random access instruction for advanced Knowledge a causation in ill-structured domains: Journal of educational technology, 31(5), 22-34.

Ronald, A. Yaros. (2011). Effects of Text and Hypertext Structures on User Interest and Understanding: Science and Technology.285-295

Schank, R. C., \& Abelson, R. P. (1977). Scripts, plans, goals, and understanding. Hillsdale, NJ: Erlbaum

Shaie, K., Dutta, R. \& Willis, Sh. (1991). Relationship Between Rigidity-Flexibility and Cognitive Abilities in Adulthood. Psychology and Aging, 6(3), 371- 383.

Shirk, H. N. (1992). Cognitive architecture in hypermedia instruction. In E. Barrett (Ed.), Sociomedia: Multimedia, hypermedia, and the social construction of knowledge (pp. 79-93). Cambridge: MIT Press.

Skinner, B. F. (1954). The science of learning and the art of teaching. Harvard Educational Review, 24, 86-97.

Su, Y. \& Klein, J. (2006). Effects of Navigation Tools and Computer Confidence on Performance and Attitudes in a Hypermedia Learning Environment. Journal of Educational Multimedia and Hypermedia, 15(1), 87-106. Retrieved March 6, 2014 from http://www.editlib.org/p/6118. 
Vrugt, A. \& Oort, F. J. (2008). Metacognition, achievement goals, study strategies and academic achievement: Pathways to achievement. Metacognition Learning, 30, 123-146.

Walter, Dick. (1991). an instructional designer's view of constructivism: Journal of educational technology, 31(5), 42.

Warr, P., and Downing, J. (2000). Learning strategies, learning anxiety, and knowledge acquisition. British Journal of Psychology, 91, 311-333.

Wiley, D. A. (2002). Connecting learning objects to instructional design theory: A definition, a metaphor, and a taxonomy. In D. A.

Yaros, R. A. (2005). Communicating complex news: Structuring stories to enhance public engagement and understanding of science. Paper presented at the Association for Education in Journalism \& Mass Communication, San Antonio, TX.

Yu-hui Ching Yu-chang Hsu Huifen Lin Francis Dwyer (). Different Levels of Learning Achievement in a Web-based Environment with Animation Lawless, K. A., \& B

Zimmerman, B. J., \& Kitsantas, A. (2005). The hidden dimension of personal competence: Self-regulated learning and practice. In A. j. Elliot, \& C. S. Dweck (Eds.). Handbook of Competence and Motivation, (Pp. 509526). New York: The Guilford Press.

Zimmerman, B. J., \& Martinez-Pons, M. (1988). Construct validation of a strategy model of student self-regulated learning. Journal of Educational Psychology, 80, 284-290 